\title{
ARTIMIS TELEPHONE TRAVEL INFORMATION SERVICE: \\ Current Use Patterns and User Satisfaction
}

Report No. KTC-99-24

"Evaluation of ARTIMIS Telephone Information System"

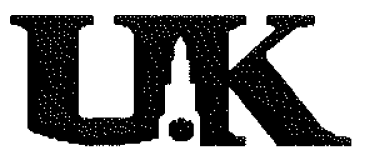

Jill Clemons

Lisa Aultman-Hall

Sarah Bowling

Department of Civil Engineering and Kentucky Transportation Center University of Kentucky

The contents of this report reflect the views of the authors, who are responsible for the facts and accuracy of the data presented herein. The contents do not necessarily reflect the official views or policies of the University of Kentucky, the Kentucky Transportation Cabinet, the Ohio Department of Transportation, or the Federal Highway Administration. This report does not constitute a standard, specification, or regulation. 


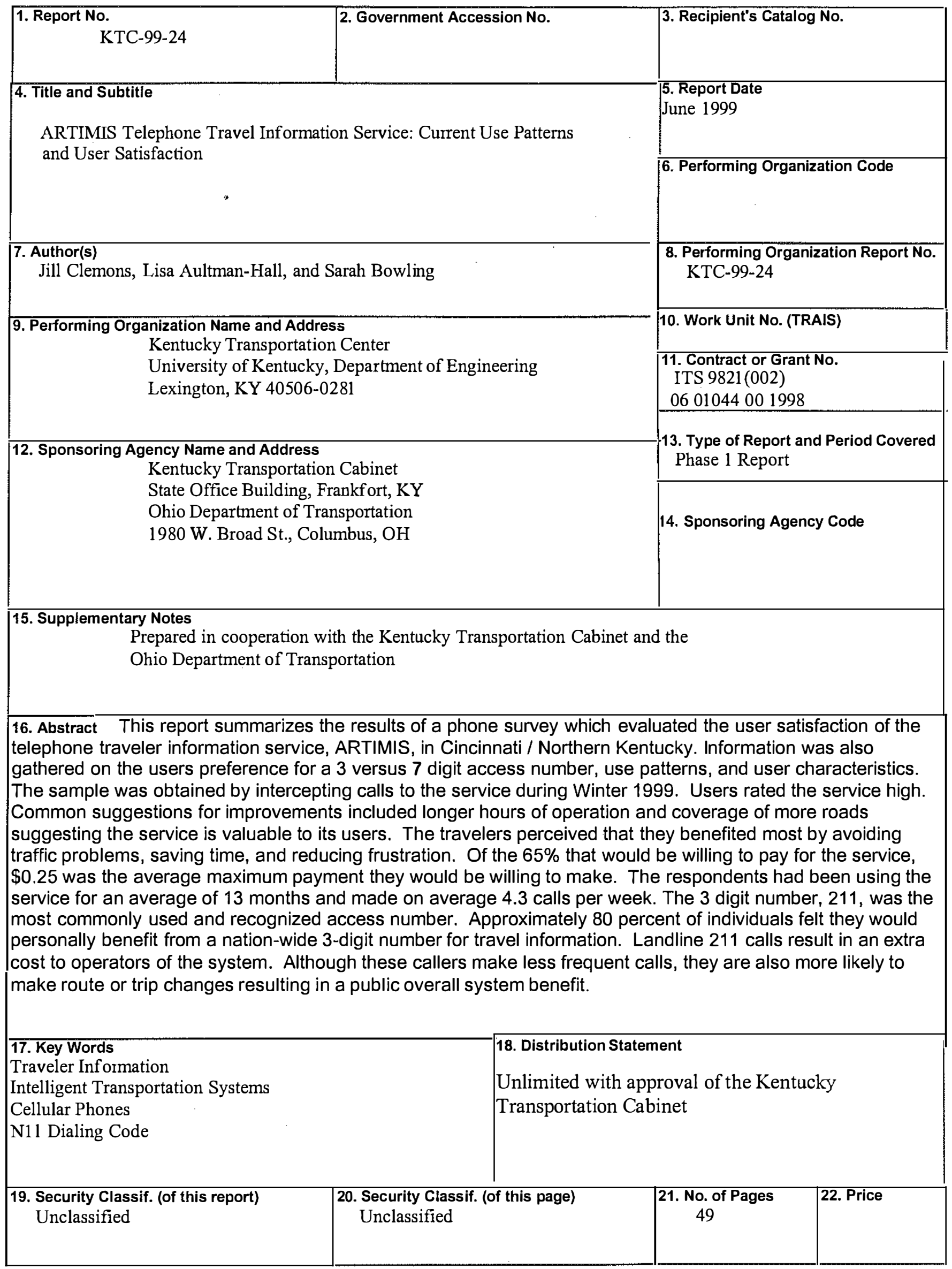


TABLE OF CONTENTS

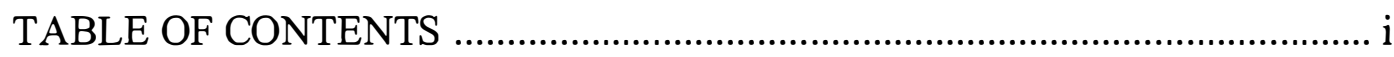

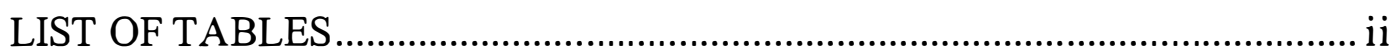

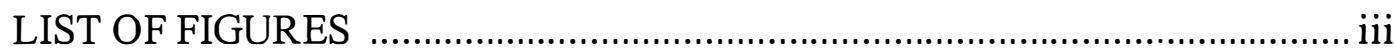

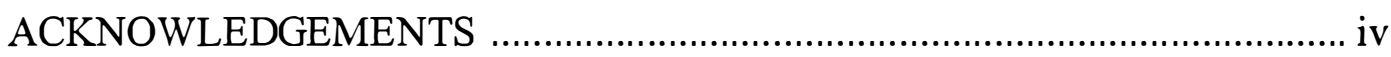

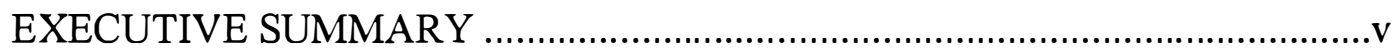

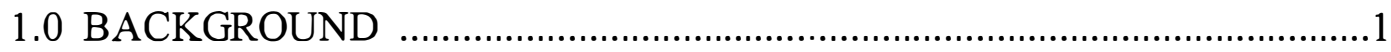

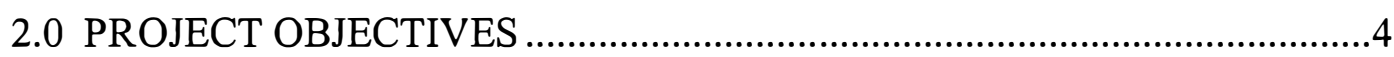

3.0 CALL HISTORY

4.0 SURVEY METHODOLOGY \& INTERCEPT SURVEY EXECUTION.....10

4.1 Survey Design ...................................................................................

4.2 Intercept Survey Execution...............................................................11

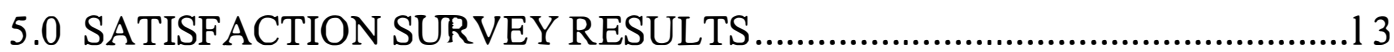

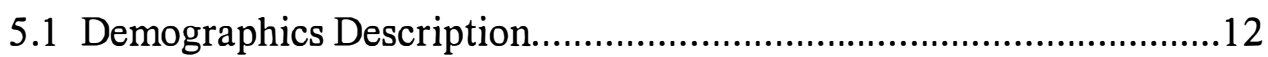

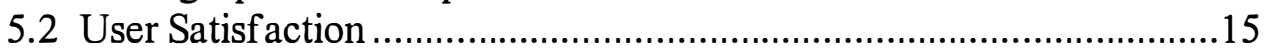

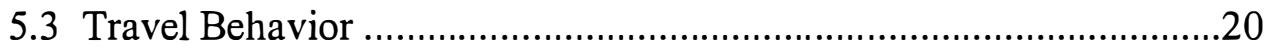

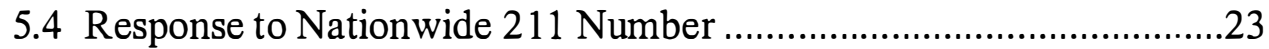

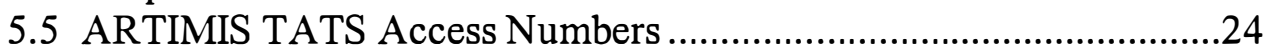

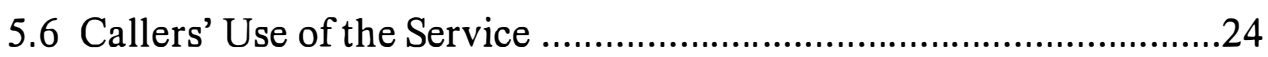

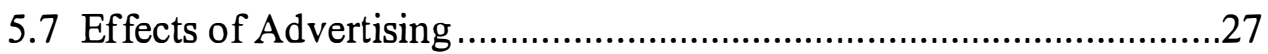

5.8 Costs and Willingness to Pay.........................................................27

5.9 Characteristics of the Landline 211 Callers .........................................29

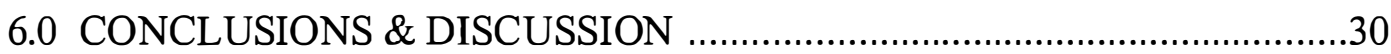

6.1 Traveler Service Satisfaction .........................................................

6.2 Travel Behavior and Service Use ...................................................31

6.3 Nationwide N11 Traveler Information Dialing Code...........................31

APPENDIX 


\section{LIST OF TABLES}

Table 1: Intercept Survey Schedule 11

Table 2: Respondents' Education Levels.........................................................14

Table 3: Respondents' Income Levels ...........................................................14

Table 4: Rating of the Accuracy of ARTIMIS TATS ........................................19

Table 5: Rating of the Ease of Use of ARTIMIS TATS........................................19

Table 6: Suggested ARTIMIS TATS Improvements ...........................................19 


\section{LIST OF FIGURES}

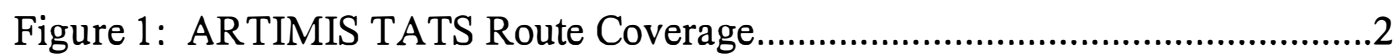

Figure 2: Landline and Cellular Calls to ARTIMIS TATS ..................................

Figure 3: Total ARTIMIS TATS Calls..........................................................

Figure 4: Cellular Provider B Cellular Calls.......................................................

Figure 5: Affects of Radio and Television Broadcasts on Landline and Cellular

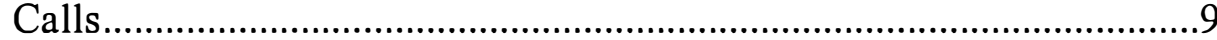

Figure 6: Frequency of Access Number Use .....................................................12

Figure 7: Percentage of Calls to ARTIMIS TATS ………....................................13

Figure 8: Respondents' Ages ................................................................................14

Figure 9: Call Count Delineated by Zip Code ………….....................................16

Figure 10: Cellular Phone Ownership by Age ......................................................17

Figure 11: Cellular Providers of Callers.............................................................17

Figure 12: Overall Rating of ARTIMIS TATS...................................................18

Figure 13: Perceived Benefits of ARTIMIS TATS ..............................................18

Figure 14: Locations That Callers Ever Call From..................................................21

Figure 15: Locations That Callers Usually Call From............................................21

Figure 16: Trip Destination of ARTIMIS TATS Callers........................................22

Figure 17: Frequency ARTIMIS TATS Users Travel Alone .................................22

Figure 18: Changes in Travel Behavior of ARTIMIS TATS Users ......................23

Figure 19: Months Respondents Have Been Aware of ARTIMIS TATS .............25

Figure 20: Frequency of Calls to ARTIMIS TATS ..............................................26

Figure 21: Time of Day When People Call ARTIMIS TATS ...............................26

Figure 22: Motivation to Call ARTIMIS TATS ..................................................27

Figure 23: Other Sources of Travel Information .................................................28

Figure 24: First Awareness of ARTIMIS TATS ………………………….......28

Figure 25: Who Do You Think Pays for ARTIMIS TATS? ..................................30 


\section{ACKNOWLEDGEMENTS}

The work described in this report was the combined effort of many individuals.

Important contributions were made by Jennifer Walton and Jerry Pigman of the Kentucky Transportation Center. Ron Langley and his team at the University of Kentucky Survey Research Center were responsible for the execution of the survey work. Members of the research advisory committee, Jane Lappin, US DOT Volpe Center; Joseph Bassil, Ohio DOT; Robert Bross, SmartRoute Systems; Scott Evans, TRW/ARTIMIS; Glenn Jilek, FHWA; Al Alonzi, FHWA; Bill Jones, FHWA; Chuck Knowles, KYTC; Nancy

Albright, KYTC; Amy Dougherty, Kentucky Public Service Commission; and Dory Montazemi, OKI Regional Council of Govemments, were very supportive in providing input to survey design. Finally, Leon Walden of the Kentucky Transportation Cabinet should be credited with developing the vision for this research project and conscientiously overseeing its implementation. 


\section{EXECUTIVE SUMMARY}

In February and March 1999, an ARTIMIS ${ }^{1}$ Traffic Advisory Telephone Service (ARTIMIS TATS) user satisfaction survey was conducted by the University of Kentucky on behalf of the Kentucky Transportation Cabinet (KYTC) and the Ohio Department of Transportation (ODOT). The survey effort had three main objectives: 1) to assess the overall satisfaction and effectiveness of ARTIMIS TATS; 2) to determine the prevalence and preference of accessing the service through the use of a N11 dialing code; and 3) to determine the influence of the traveler information on travel behavior. A random telephone survey of households in the Cincinnati / Northern Kentucky area will be undertaken in the summer of 1999 to determine the general awareness and use of the service.

Users of ARTIMIS TATS were invited to participate in the satisfaction survey by intercepting their calls to the service. A total of 579 respondents were contacted by telephone within two to three weeks to complete the satisfaction questionnaire. Of the 1,110 calls that were intercepted to the service, 74 percent of calls had used the threedigit 211 number which is provided as an enhancement by the KYTC and ODOT. A majority of the calls intercepted, 64 percent, were made with a cellular phone.

The satisfaction survey revealed that a majority of users ( 62 percent) were male, while overall 74 percent of users had attended at least some college. Service user income levels were relatively high; two-thirds of respondents had a household income of more than $\$ 45,000$ a year. Most respondents owned a cellular phone (88 percent). Furthermore, 63 percent of those who had been intercepted making a call from a landline phone, owned a cellular phone. Owners of cellular phones reported using the cellular phone for an average 78 percent of their calls to ARTIMIS TATS.

Several measures of service satisfaction were included in the survey. When directly asked, users rated the service an average of 8 on a scale of 1 to 10 , with 10 being the best. The users also rated the service high for accuracy and ease of use. Over 99 percent of the users indicated they benefited from the service by avoiding traffic problems, saving time, reducing frustration or arriving on time. Most respondents are aware that ARTIMIS TATS, including the three-digit 211 number, are provided free of charge but are publicly funded. However, 65 percent indicated they would be willing to pay for the service, which also indicates a high level of satisfaction. On average, the maximum people would pay was $\$ 0.25$. The finding that 81 percent of users had recommended the service to a friend was also taken as an indication that these users deemed the service of value and felt it would be of value to others. When asked for suggestions for service improvements 24 percent of individuals could not suggest one, while the most common suggestions involved extending the hours of the service or the routes covered by the service. This suggestion for "more" ARTIMIS TATS is also considered an indication of high satisfaction.

\footnotetext{
${ }^{1}$ Advanced Regional Traffic Interactive Management and Information System
} 
The respondents indicated they had been using ARTIMIS for an average 13 months. The most common way people learned about the service was by radio or television. Radio was also the most common "other" source of traffic information used by the respondents. ARTIMIS TATS users indicated they call most often for information for work-related trips. They call most often from their vehicles. The average trip length for the most common trip when the users call the service was 22 miles. Users were asked what portion of the time the information provided by ARTIMIS TATS affected their travel behavior: route taken (average 71 percent of the time), departure time (average 34 percent of the time), and destination (average 25 percent of the time). The traffic information rarely affected mode used, however, users indicated on average 14 percent of the time they completely delayed their trip. These travel behavior changes have the potential for system-wide travel benefits for the area. Users indicated they called between once and 20 times per week (average 4.3). Over 50 percent of users call during the morning peak hours, while more, 80 percent, indicated they call during the afternoon/ evening peak. The majority of users indicate they are also frequently or occasionally motivated to call ARTIMIS TATS by bad weather, being late, road construction, and traffic crashes.

Each time someone dials 211 from a landline phone it costs ARTIMIS \$0.25, while two major cellular phone service providers offer 211 free of charge to their customers. Over 70 percent of the respondents intercepted calling 211 on a landline phone owned a cellular phone. These 211 landline callers contact ARTIMIS TATS slightly less often, but are more likely to change their travel behavior, which can improve overall system performance. Among all users, the 211 number is the most used and recognized for the service. Approximately 80 percent of the users felt they would personally benefit from a nationwide $\mathrm{N} 11$ dialing code for traffic information so they would not need to know local access numbers.

The respondents indicated they make on average 19 trips per year to other areas where they could use a service like ARTIMIS TATS, but only 4.3 percent had ever used a service in another city. This potential use of telephone raffic information in multiple areas by the traveling public combined with the following three study findings suggests a nation-wide 3-digit access code for traffic information would be a benefit to overall transportation system performance. First, there is a high percentage of users who change their travel behavior due to real time traffic information provided by ARTIMIS TATS. Second, users were very satisfied with ARTIMIS TATS and many called for its expansion. Finally, there was good recall and preference for the 211 number currently provided in Northern Kentucky and Cincinnati by KYTC and ODOT. 


\subsection{BACKGROUND}

The Advanced Regional Traffic Interactive Management and Information System (ARTIMIS) is a regional traffic management system provided by the Kentucky Transportation Cabinet (KYTC), Ohio Department of Transportation (ODOT), Federal Highway Administration (FHWA), Ohio-Kentucky-Indiana (OKI) Regional Council of Govermnents, and the City of Cincinnati. ARTIMIS has two major functions, specifically, Advanced Traf fic Management Systems (ATMS) and Advanced Traveler Information Systems (ATIS). ARTIMIS serves the Cincinnati / Northern Kentucky urbanized area and a large volume of through traffic. In June 1995, ARTIMIS began a telephone information service as part of the ATIS function. This service, known as SmarTraveler, is but one component of the ATIS function and is hereinafter referred to as the ARTIMIS Traveler Advisory Telephone Service or ARTIMIS TATS. Three-digit numbers (211 and 311) were introduced to contact ARTIMIS TATS so callers would not have to remember or dial a seven-digit number. The 211 and 311 numbers are not a part of the SmarTraveler component but an enhancement provided by the KYTC and ODOT.

As it becomes more difficult to expand capacity to accommodate the increase in vehicle usage, ATIS services can alleviate many of the problems associated with traffic congestion in urban and rural areas. ATIS services, available in many cities in the United States, affect certain aspects of a person's travel behavior, such as route choice, departure time, decision to make the trip, or mode choice. These individual traveler changes can improve overall travel system performance by making travel less time consuming, more convenient and improving travel time for all system users. Travel information is available from several different sources, including radio, television, Internet, newspaper, telephone, changeable message signs, and route guidance provided by in-vehicle navigation systems. ARTIMIS TATS has become an important aspect of ATIS for the Cincinnati / Northern Kentucky area.

ARTIMIS TATS provides real-time traveler information to anyone in the local telephone service calling area who calls $211,311^{2}$, or $333-3333$. Outside of the local calling area, travelers can dial (513) 333-3333 to reach the service. Callers can select a specific route or route segment from the system's main menu to receive a current report on traffic conditions. The routes covered by ARTIMIS TATS can be seen in Figure 1. The traffic reports are updated continuously from 6:00 a.m. to 7:00 p.m., Monday through Friday. Construction and transit information is available 24 hours a day, 7 days a week.

ARTIMIS uses many devices and sources to provide up-to-date affic information. Devices include closed circuit video cameras, radar detectors, video imaging detectors, reference markers, and inductive loops. Other sources include freeway service patrols, one aircraft, a network of drivers who serve as probes, police, fire departments, emergency communicators, and construction personnel. ARTIMIS personnel are able to provide very comprehensive and accurate ATIS functions.

\footnotetext{
${ }^{2}$ Please note that although 311 is still available, since the local telephone service provider has not cut off the availability of that number, its promotion and advertisement has been discontinued.
} 
Figure 1: ARTIMIS TATS Route Coverage

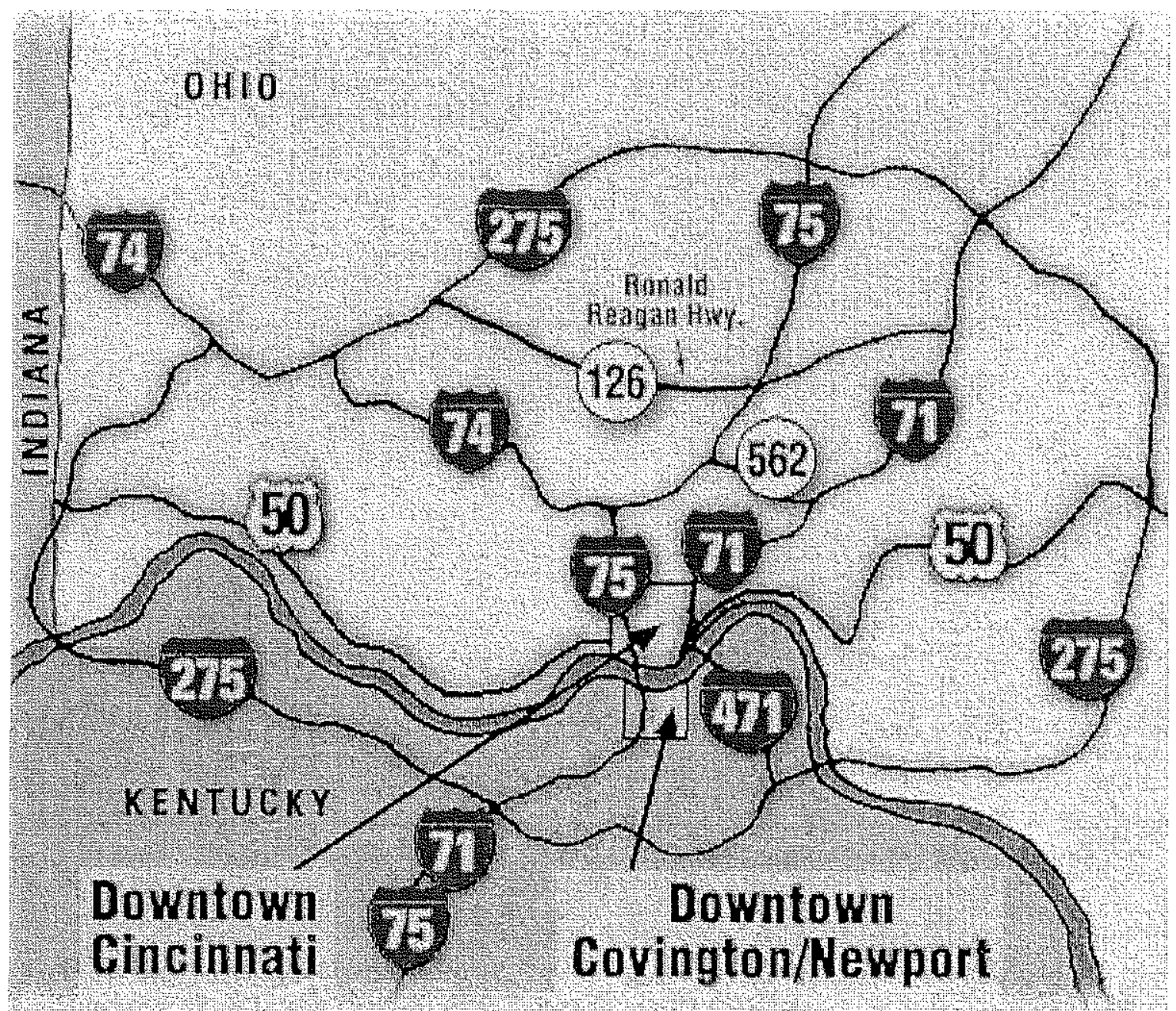

ARTIMIS TATS is currently receiving over 80,000 calls per month. The calls are approximately 65 percent landline calls and 35 percent cellular telephone calls. However, the number of landline and cellular callers, shown in Figure 2, has fluctuated greatly throughout the life of the service. The patterns and peaks of Figure 2 will be discussed later. There is no cost to landline or most cellular phone users in the area, but out-of-the-area callers may incur long distance or roaming charges. The cost to ARTIMIS is about $\$ 0.25$ per landline 211 call. There is no cost to ARTIMIS for a 3333333 call. Four cellular providers currently waive airtime charges for 211 access for their customers. Two other cellular carriers are considering the same arrangement. Any cellular customer can dial 333-3333, but airtime charges will apply.

Initially, the seven-digit number, 333-3333, was used to access ARTIMIS TATS. In November 1995, callers in the Northern Kentucky portion of the area began to use 311, the first such usage in the nation for traveler information. However, in February 1997, the 311 number was reserved by the Federal Communications Commission (FCC) as a nationwide non-emergency public agency number. The 311 number is presently in use in several cities including Baltimore, San Jose, and Dallas. In order to avoid potential 
Figure 2: Landline and Cellular Calls to ARTIMIS TATS

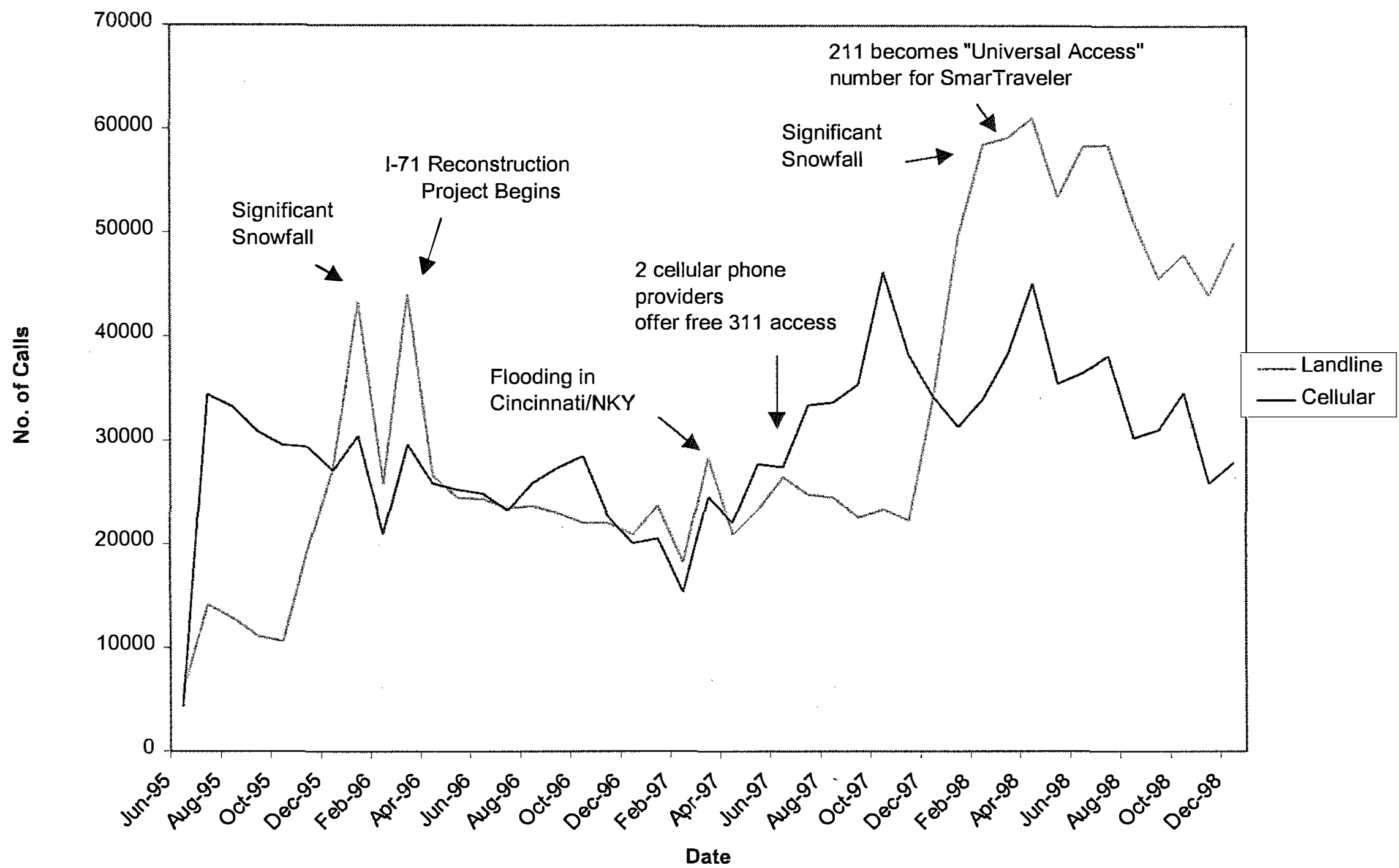


conflicts and implementation issues, the ARTIMIS project sponsors decided to seek another N11 dialing code. Subsequently in March of 1998, after action by the Kentucky Public Service Commission and the Public Utilities Commission of Ohio, the 211 number became available in the Cincinnati / Northern Kentucky area for travel information. Currently, the 211 number is operational in the major portion of the urbanized area of Cincinnati and in six counties in Kentucky. Ohio residents not in the local exchange carrier's (LEC) service area can only reach the service by calling the 333-3333 number.

On March 8, 1999, after the Federal Highway Administration (FHWA) had prepared a petition for a nationwide N11 dialing code, the United States Department of Transportation (USDOT) formally petitioned the FCC for the N11 dialing code that could be used to obtain traveler information across the United States. On April 13, 1999, an article in USA Today presented a valid, nationwide, case for an N11 dialing code. On April 20, 1999, the FCC issued a Public Notice on the USDOT petition, thereby formally beginning the regulatory process to consider the USDOT petition.

\subsection{PROJECT OBJECTIVES}

In 1998, in response to the federal interest in establishing N11 as a national traveler information number and a desire to evaluate the success and awareness of ARTIMIS TATS, the KYTC initiated a research project jointly funded by FHWA, KYTC, and ODOT. The benefits of a national N11 dialing code and the satisfaction and awareness of the traveler information number in Cincinnati / Northern Kentucky were to be assessed through surveying users of the system as well as a random sample of individuals in the area.

The following are the formal objectives that this project was created to meet:

- to assess the overall satisfaction and effectiveness of ARTIMIS TATS;

- to determine the general awareness of ARTIMIS TATS in the regional coverage area;

- to determine the prevalence and preference of accessing the service through the use of a N11 dialing code, such as 211 , versus a seven-digit number; and

- to determine the influence of traveler information on travel behavior.

Specifically, research and survey questions were implemented to obtain the following information:

- relative number of calls from both cellular phone and landline users;

- perceived accuracy of the information received from the service;

- frequency of use;

- trip types (purpose) when using the service;

- change in route, departure time, or destination resulting from travel information;

- typical origins/destinations;

- preference for 3-digit versus 7-digit number;

- use of other sources of travel information;

- perceived benefits received from the service; 
- motivations for service use;

- user satisfaction with the service;

- general public awareness of the service; and

- personal/demographic characteristics of the users and non-users.

All of this information is to be used, among other purposes, for KYTC and ODOT to determine if the cost of landline usage of 211 versus a seven-digit number is generating sufficient benefits to continue its usage.

In order to accomplish these objectives, two surveys were designed and undertaken. ARTIMIS TATS users were invited to participate in the first survey, by intercepting their calls into the system. At that time two brief questions were asked, however, the followup telephone satisfaction survey was completed within the next two weeks. The second survey, an awareness survey, was designed as a random-digit dial survey for people in the ARTIMIS coverage area.

This report includes an overview of the call history to ARTIMIS, the satisfaction survey methodology, the satisfaction surveys results, and conclusions on these results. Data from the second survey, the awareness survey, is not yet available.

\subsection{CALL HISTORY}

The number of calls coming from both landline and cellular phones to ARTIMIS TATS was analyzed from the beginning of the service's operation in June 1995, until December 1998. The analysis was performed in order to evaluate the effect of the number of calls (cellular and landline) into the service on road reconstruction, weather conditions, cellular phone charges to access ARTIMIS TATS, and radio and television broadcasts of the service. The call history used in the analysis was collected by ARTIMIS and provided to the University of Kentucky at the beginning of the study. At the time of the analysis, ARTIMIS had four telephone nodes coming into the service. There was a landline, Cellular Provider $\mathrm{A}^{3}$, Cellular Provider B, and an overflow node. The landline node received calls from regular (non-cellular) phones. The Cellular Provider A and Cellular Provider B nodes only received calls from their respective cellular providers. The overflow node was used when a large number of calls entered the system. However, it also received calls from newer cellular providers as well as the overflow calls from the other nodes. ARTIMIS personnel estimated that 1.5 percent and 4.5 percent of calls going into this node were from Cellular Provider $\mathrm{C}$ and Cellular Provider $\mathrm{D}$, respectively. This amount is taken away from the total number of calls into that node to find the estimated number of overflow calls from other sources, such as landline. The number of calls, cellular and landline, into the service fluctuated over the life of the service in response to many of the conditions mentioned previously.

Months experiencing bad weather had a greater than average number of calls to the service. There were very large accumulations of snow in January 1996 and February

\footnotetext{
${ }^{3}$ Here and throughout this report the cellular phone providers are referred to in this format to avoid advertisement or miscommunication of corporate policies.
} 
1998 that notably increased the calls into the service. Users of the service could call to determine the conditions of particular routes and to see if there were any incidents that might cause delays in travel time. Figure 2 indicates that call increases during these months were mostly from landline callers.

Roadway reconstruction is an on-going process in the ARTIMIS coverage area, as it is in most major U.S. urban areas. Roadway reconstruction can cause lengthy traffic delays that greatly increase the use of any ATIS service. In addition to real-time information, ARTIMIS TATS provides continuous information on roadway reconstruction 24 hours a day, 7 days a week for the convenience of the callers. Information that suggests that roadway reconstruction motivates calls to ARTIMIS can be viewed in Figure 3. A large increase in calls occurred in March 1996 when the reconstruction of I-71 began in the area. The largest number of calls per month (106,175 calls) was reported in April 1998, the month that reconstruction began on the Brent Spence Bridge and Fort Washington Way (I-71) in downtown Cincinnati.

In Figure 4, a definite trend can be followed for the Cellular Provider B calls which indicates cost also affects people's inclination to call ARTIMIS TATS. In September 1995, Cellular Provider B began charging customers airtime charges for calls to ARTIMIS via the 311 access number and calls to ARTIMIS decreased drastically. The calls leveled off in 1996 for about 8 months and then again decreased in number until Cellular Provider B stopped airtime charges for 311 access to ARTIMIS in May of 1997. Cellular Provider B calls increased by approximately 5000 calls per month in just a few months. This suggests that many ARTIMIS TATS users were not willing to pay for access to the service.

When ARTIMIS TATS first began, there were generally more cellular calls than landline calls (see Figure 5). The number of landline calls began to increase toward the end of 1995. This could have been spurred by WCPO-TV broadcasts that started in October 1995. Landline and cellular phone calls were almost equal again in the middle of 1996. Radio broadcasts of the service were aired in August 1996 and July 1997 which seem to have caused a slight and short-lived increase in the number of cellular phone calls. It appears that landline callers into the service were affected by the television broadcasts and cellular phone callers were affected by the radio broadcasts. Beginning in 1998, the percentage of landline calls greatly increased due to bad weather and major reconstruction projects including the reconstruction on Fort Washington Way, which led to significant press coverage of ARTIMIS TATS. But, as stated previously, the many peaks and changes in this graph suggest ARTIMIS TATS usage is a function of many variables. 
Figure 3: Total ARTIMIS TATS Calls

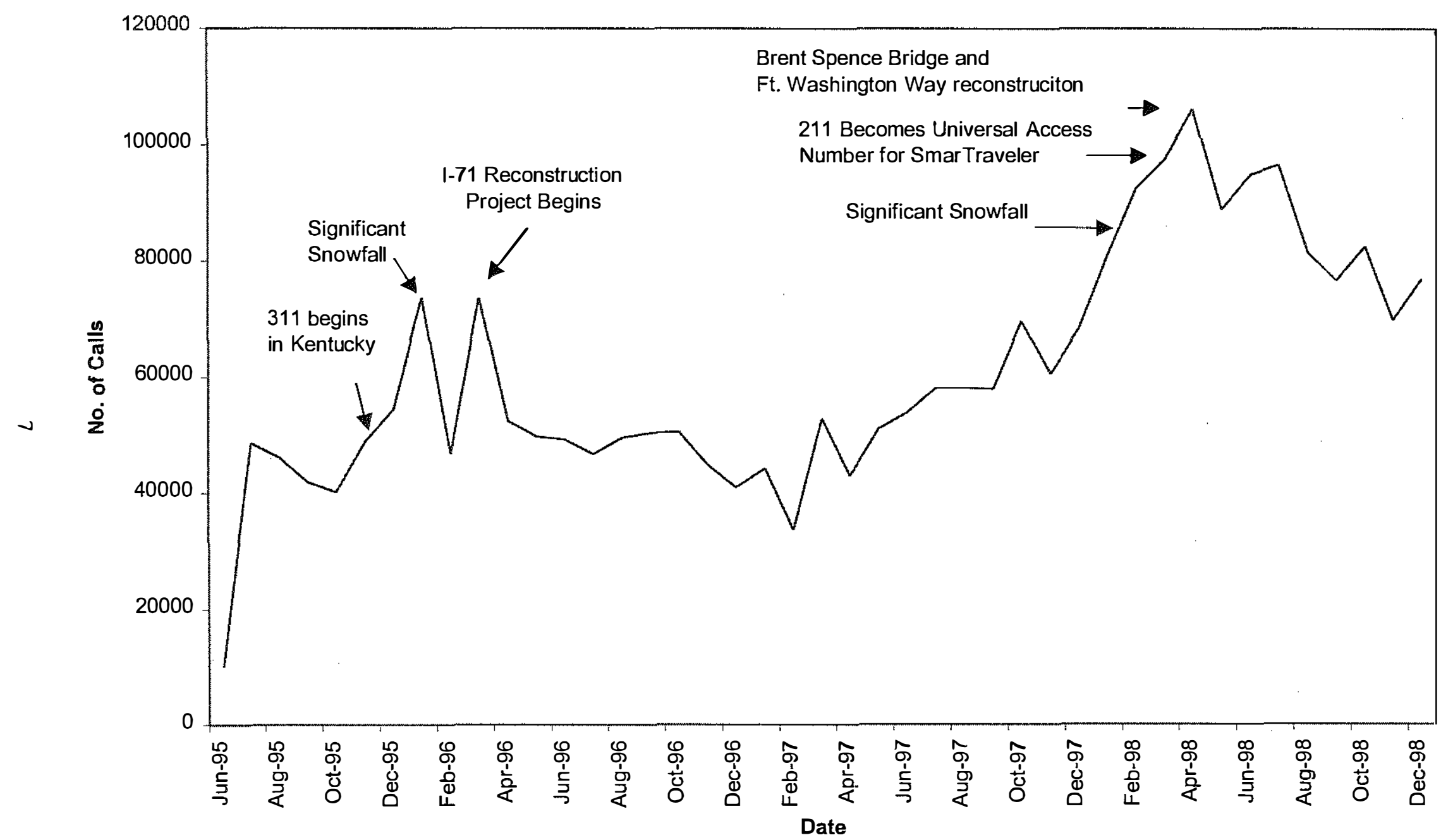


Figure 4: Cellular Provider B Cellular Calls

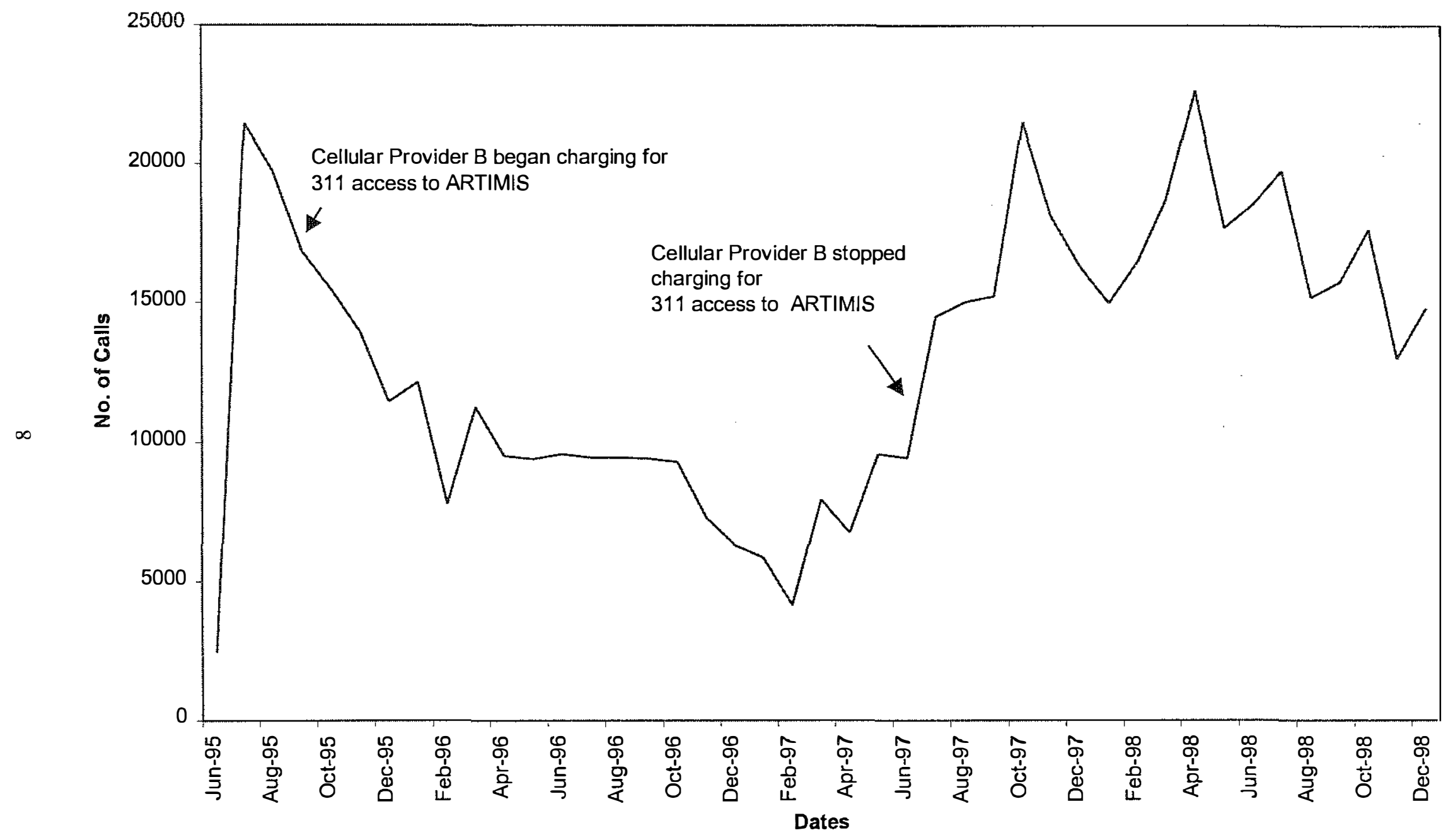


Figure 5: Affects of Radio and Television Broadcasts on Landline and Cellular Calls

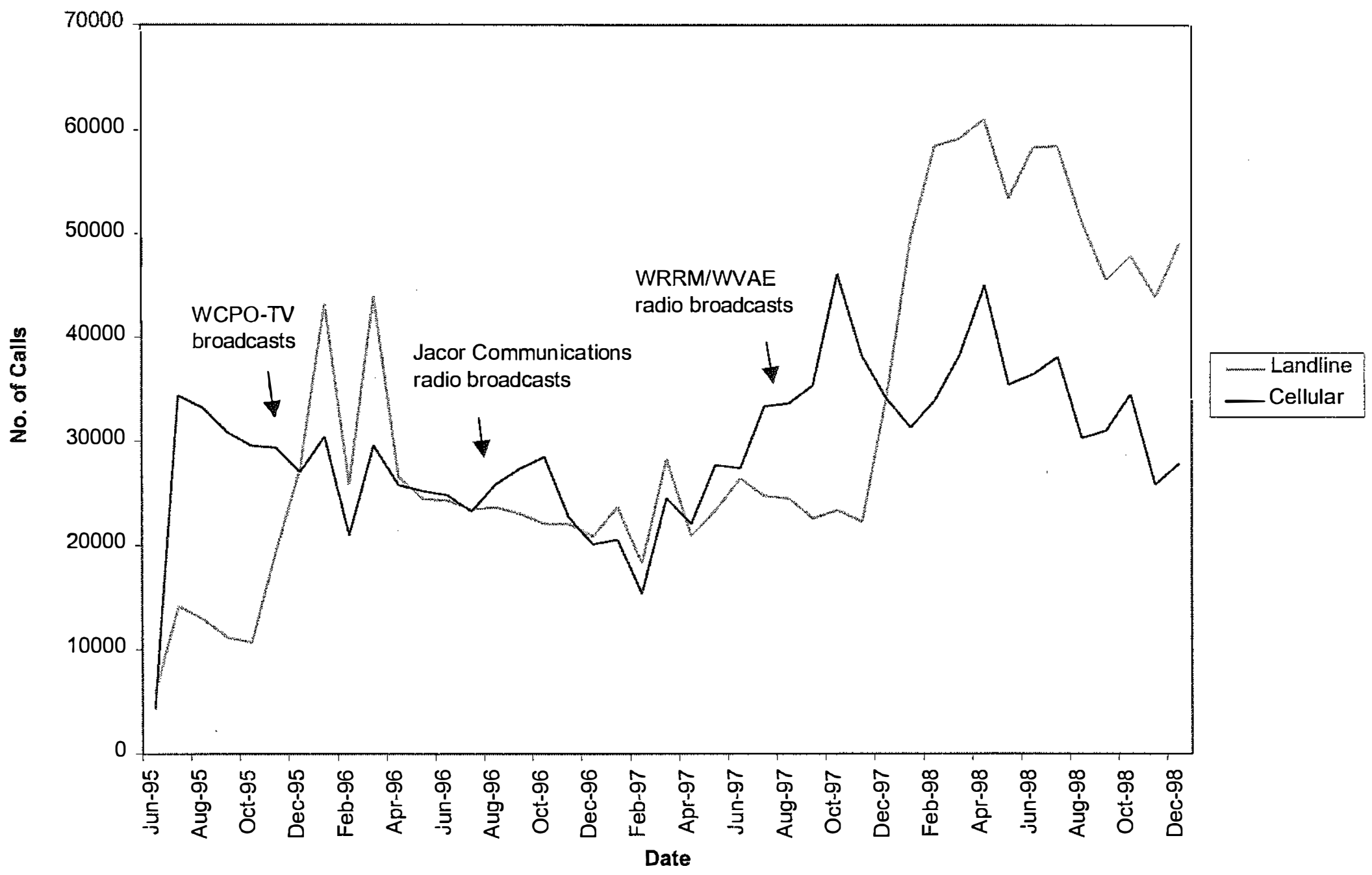




\subsection{SURVEY METHODOLOGY AND INTERCEPT SURVEY EXECUTION}

\subsection{Survey Desigu}

A copy of the intercept and subsequent satisfaction survey questionnaires designed by the Kentucky Transportation Center for this evaluation can be found in Appendix A. All of the individuals who completed the surveys were users of the freeways covered by ARTIMIS and at least 18 years old. The intercept survey of callers into ARTIMIS TATS was performed at the ARTIMIS Control Center in Cincinnati. Members of the University of Kentucky Survey Research Center ${ }^{4}$ (UK-SRC) intercepted calls into the service and asked the callers a few questions before connecting them to the service. The telephone number and the first name of those who agreed to participate in the satisfaction survey were recorded so that they could be contacted at a later time. The main purpose of the intercept survey was to ask the callers to participate in the satisfaction survey that was to take place within two or three weeks after the intercept survey. The intercept survey was also used to obtain the percentage of landline and cellular phone callers and to determine which number the caller used to contact ARTIMIS.

The satisfaction survey was also performed by the UK-SRC. These surveys were conducted from the University of Kentucky campus where those performing the survey were aided by the use of computers that prompted them with the survey questions on the screen and allowed them to enter the response. This process eliminated the need to later enter the data into a database. The satisfaction survey, which was approximately 10 minutes long, asked ARTIMIS TATS callers about their use and satisfaction of the TATS. Responses from this survey are the focus of most of this report. A second survey will be a random-digit phone survey to determine the awareness of the service in the Cincinnati / Northern Kentucky area. This survey will be conducted in July 1999.

The intercept survey was very brief. UK-SRC personnel and the Technical Advisory Committee for the research project reviewed the intercept survey questionnaire. The intercept survey included questions regarding the use of cellular or landline phones and the phone number the respondents called to access the service. During the review process some questions were removed from the intercept survey and placed in the satisfaction survey so that the intercept survey would be less time consuming.

The user satisfaction survey was reviewed by the same individuals who reviewed the intercept survey. Originally, the satisfaction survey contained only questions regarding the satisfaction of the service, travel behavior of the users, phone numbers, and type of phone used to connect to ARTIMIS TATS. On the recommendation of the Technical Advisory Committee questions were added to address issues not mentioned in the original satisfaction survey, as follows:

\footnotetext{
${ }^{4}$ The UK Survey Research Center conducts socially significant research with public policy implications as well as research of theoretical or academic interest. UK-SRC has conducted more than 340 studies since it was established in 1979. It uses the ACS-Query Computer-Assisted Telephone Interviewing (CATI) system, a 16-line telephone bank, and 20 computers.
} 
- respondent's personal demographic characteristics;

- use of similar services in other cities; and

- awareness questions regarding first use of ARTIMIS TATS, telephone numbers, and cost to the caller.

Five interviews were performed on actual respondents as a pretest and minor wording changes were made as a result.

Two different time periods (7:00 AM to 12:00 PM and 2:00 PM to 7:00 PM) were used for the intercept surveys. These times were chosen so the survey would intercept callers during both the peak morning and afternoon periods of service use. The follow-up satisfaction survey was performed within three weeks after the intercept survey so respondents would remember agreeing to paricipate in the survey. The Technical Advisory Committee for the project agreed that the UK-SRC should aim for a total of 600 completed intercept surveys and 500 completed satisfaction surveys.

\subsection{Intercept Survey Execution}

The UK-SRC provided guidance in the survey design process and administered the phone surveys. The intercept survey was performed in the first two weeks of February and the second week of March 1999. The surveys were undertaken in the morning period (7:00 AM to 12:00 PM) for four days and in the evening period (2:00 PM to 7:00 PM) for seven days (see Table 1). Intercept surveys were performed every day of the week.

Table 1: Intercept Survey Schedule

\begin{tabular}{|l|l|l|l|l|l|}
\hline Week & Monday & Tuesday & Wednesday & Thursday & Friday \\
\hline February & No Surveys & $10: 00 \mathrm{am}-$ & $2: 00 \mathrm{pm}-$ & $2: 00 \mathrm{pm}-$ & $7: 00 \mathrm{am}-$ \\
$\mathbf{1}^{\text {st }}-\mathbf{5}^{\text {th }}$ & performed. & $12: 00 \mathrm{pm}$ & $7: 00 \mathrm{pm}$ & $7: 00 \mathrm{pm}$ & $12: 00 \mathrm{pm}$ \\
\hline February & $7: 00 \mathrm{am}-$ & No Surveys & $2: 00 \mathrm{pm}-$ & $2: 00 \mathrm{pm}-$ & No Surveys \\
$\mathbf{8}^{\text {th }}-\mathbf{1 2}^{\text {th }}$ & $12: 00 \mathrm{pm}$ & performed. & $7: 00 \mathrm{pm}$ & $7: 00 \mathrm{pm}$ & Performed. \\
\hline March & No Surveys & $2: 00 \mathrm{pm}-$ & $7: 00 \mathrm{am}-$ & $2: 00 \mathrm{pm}-$ & $2: 00 \mathrm{pm}-$ \\
$\mathbf{8}^{\text {th }}-\mathbf{1 2}^{\text {th }}$ & Performed. & $7: 00 \mathrm{pm}$ & $12: 00 \mathrm{pm}$ & $7: 00 \mathrm{pm}$ & $7: 00 \mathrm{pm}$ \\
\hline
\end{tabular}

Originally, there were two weeks of intercept surveys performed with a total of 590 people agreeing to participate in the satisfaction survey. Only 390 of the 590 satisfaction surveys could be completed due to problems contacting the individuals or refusals; therefore, more intercept surveys were performed in March to recruit more satisfaction survey participants.

Eventually, there was a total of 1,110 people who participated in the intercept survey and 891 ( 80.3 percent) of these people agreed to participate in the satisfaction survey. The satisfaction surveys were performed in February and March 1999. A total of 579 of the individuals who agreed to be contacted for the satisfaction survey completed it. The 
number of intercept and satisfaction surveys completed exceeded the number originally deemed necessary to obtain adequate confidence levels in the responses.

There are three numbers $(211,311$, and 333-3333) that can be dialed in the Cincinnati / Northern Kentucky area to reach ARTIMIS TATS. Based on the intercept survey, the 211 number accounted for 73.9 percent of the numbers dialed into the service with 3333333 and 311 following at 15.9 and 9.5 percent, respectively. The relative use of the numbers can be seen in Figure 6. Eight people did not know what number they used to access the service.

Figure 6: Frequency of Access Number Use

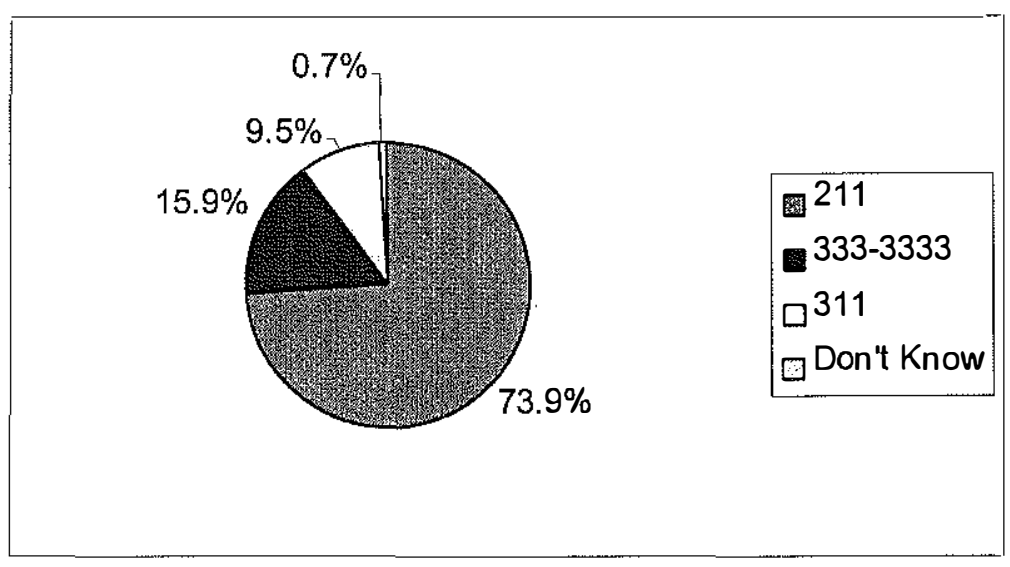

Of the people who completed the intercept survey, 64.3 percent used a cellular phone to contact the service. The rela ve percentage of callers using a cellular versus a landline phone dialing the different ARTIMIS TATS access numbers is significant. Figure 7 shows that the cellular phone users dialed the 211 number 83.5 percent of the time compared to 56.6 percent for the landline calls. The greater number of cellular calls may be due to free airtime for most cellular providers when dialing the 211 number. The 311 number is still used of ten by cellular providers ( 13.5 percent), but rarely by landline callers ( 2.3 percent). The 311 access number remains serviceable as the local exchange provider has not discontinued the availability of this number. The 333-3333 number is used more by landline callers with 40.2 percent using that number to access ARTIMIS TATS. Only 2.5 percent of the cellular phone users dialed 333-3333 to contact the service. This number remains available as the local exchange carrier has to keep it available to callers from outside its service area. 
Figure 7: Percentage of Calls to ARTIMIS TATS

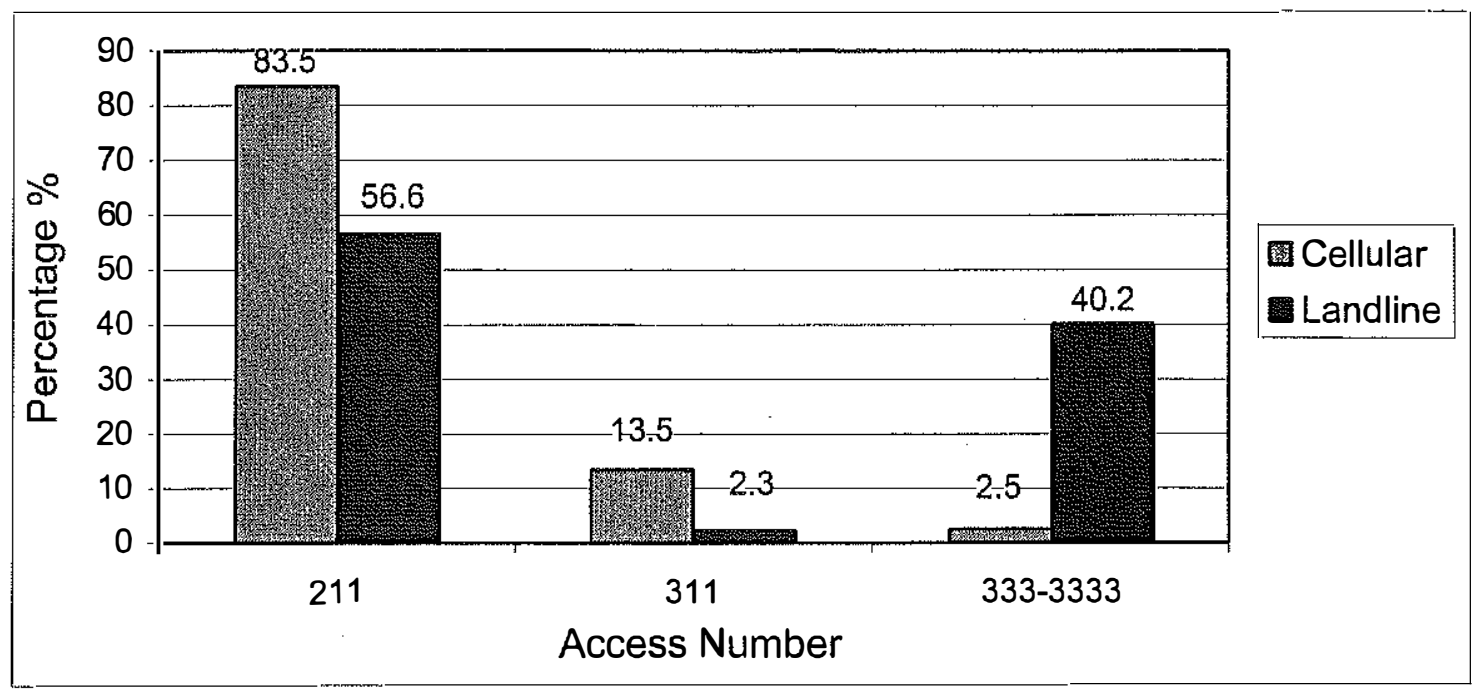

\subsection{SATISFACTION SURVEY RESULTS}

The satisfaction survey collected information about several subjects including the following: demographic characteristics of those surveyed, their satisfaction with the service, issues related to a nationwide 211 traveler information number, ARTIMIS TATS access numbers, usage patterns of the service, costs, the effects of advertising, and the travel behavior of the callers. A detailed analysis of landline 211 calls was performed as these calls result in a cost to KYTC and ODOT.

\subsection{Demographics Description}

When analyzing a service it is always important to know the demographic characteristics of people using that service in order to improve and meet the needs of its users. Demographic questions which pertained to the callers' gender, age, level of education, income, geographic location, and pattern of cellular phone usage were included in the satisfaction survey.

The respondent's gender was recorded by the UK-SRC without actually asking the respondent. Respondents consisted of 62.3 percent males and 37.7 percent females. The average age was 43 years with a range from 19 to 79 years as shown in Figure 8. Most of the respondents had attained higher levels of education with 73.8 percent attending college. Income levels were also relatively high. Two-thirds of the respondents were from households with greater than $\$ 45,000$ gross yearly income. Education and income levels for the callers are listed in Tables 2 and 3. 
Table 2: Respondents' Education Levels

\begin{tabular}{|c|c|}
\hline Education & \% of Respondents \\
\hline Less than H.S. Diploma & 0.5 \\
\hline H.S. Graduate & 11.4 \\
\hline Some College & 26.3 \\
\hline College Degree & 36.1 \\
\hline Postgraduate Work & 25.2 \\
\hline
\end{tabular}

Table 3: Respondents' Income Levels

\begin{tabular}{|c|c|}
\hline Household Income & \% of Respondents \\
\hline Less than $\$ 25,000$ & 3.5 \\
\hline$\$ 25,000-\$ 45,000$ & 15.1 \\
\hline$\$ 45,000-\$ 65,000$ & 20.5 \\
\hline$\$ 65,000-\$ 100,000$ & 26.6 \\
\hline Greater than $\$ 100,000$ & 21.1 \\
\hline
\end{tabular}

Figure 8: Respondents' Ages

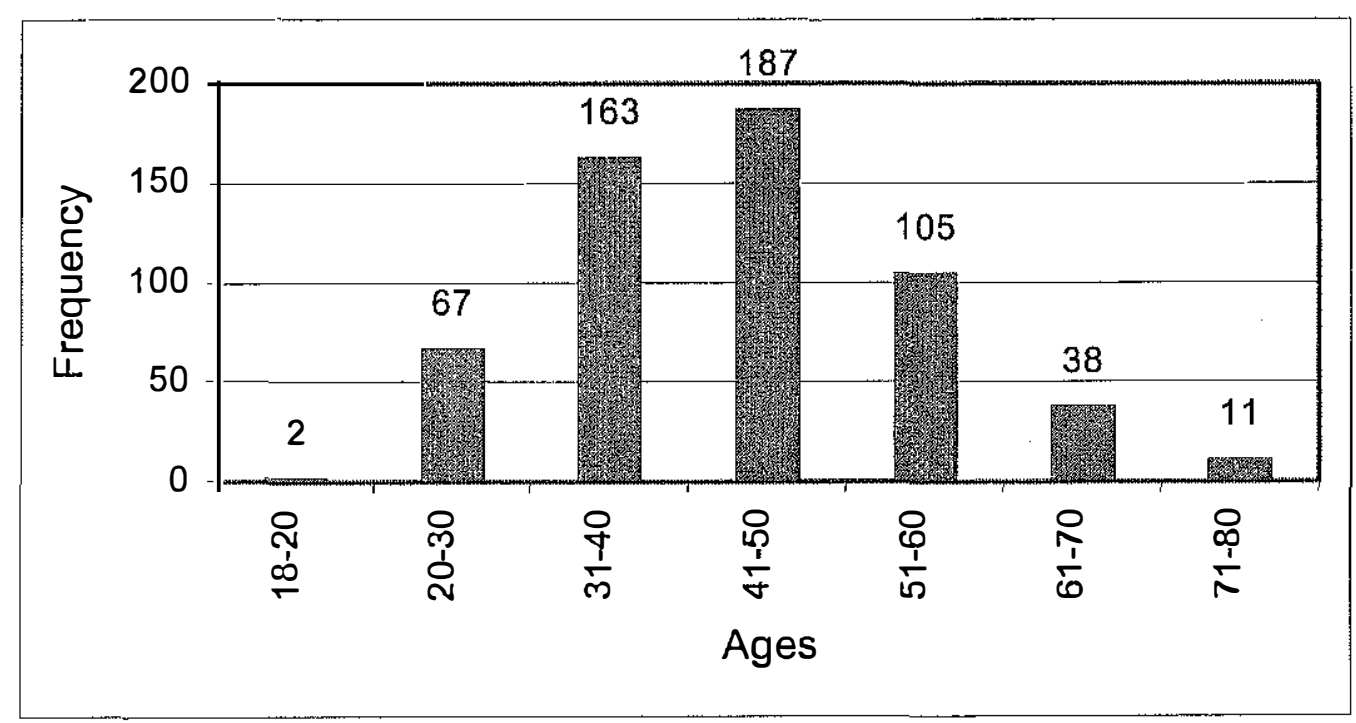


The location of the callers and the frequency of calls from each location can be seen in Figure 9. The analysis was performed by using a Geographic Information System (GIS) program and the zip code information provided by the respondents. Many of the calls were from the urban areas closer to downtown Cincinnati. The areas in white contain no survey respondents and generally reflect business and industrial areas.

Many of those surveyed (88.1 percent) owned a cellular phone. This is including 120 of the 189 people (63.4 percent) who used a landline phone to call ARTIMIS TATS. Approximately 69.0 percent of men and 65.7 percent of women surveyed owned cellular phones. According to Figure 10, the younger respondents owned cellular phones more often than the older respondents. Cellular Provider A and Cellular Provider B, the providers with their own node into the service at ARTIMIS, made up 84.3 percent of the cellular calls into the service. Cellular Provider D and Cellular Provider C had 4.5 and 3.5 percent, respectively (See Figure 11). When callers owning a cellular phone were asked what percentage of the time they used it to call ARTIMIS TATS, their responses averaged to 78.4 percent with a standard deviation of 33.0. This suggests many people use a combination of landline and cellular phones to use the service.

\subsection{User Satisfaction}

The satisfaction of ARTIMIS TATS was determined through the use of several different survey questions. ARTIMIS TATS averaged a rating of an 8.0 on a scale from one to ten, with ten being the best. In Figure 12, the frequency of ratings from all the callers is shown. The survey respondents rated ARTIMIS TATS relatively high. Cellular and landline callers rated the service very similarly. Women were slightly more likely to rate the service higher than men. A total of 81.5 percent of the callers were satisfied enough with the service to have recommended it to a friend.

Survey respondents were also asked if they benefited from ARTIMIS TATS in any of the following ways: saving time, avoiding traffic problems, arriving at a destination on time, and reducing frustration. Figure 13 illustrates that a very high percentage of the users perceived they benefited in each of these ways ( 71 percent said yes to all four benefits). Callers perceived that they benefited most by avoiding traffic problems followed by saving time, reducing frustration, and being on time. Only 6 respondents indicated they did not benefit in any of these ways. Cellular phone users indicated they benefited more often than the landline users.

When asked to rate the accuracy of the information provided by ARTIMIS TATS on a scale from 1 to 5, with 1 being not accurate at all and 5 being very accurate, over 80 percent of the callers rated the service a 4 or 5 (See Table 4). The results were similar when analyzing the ease of use on a scale ranging from 1 to 5 , with 1 being very confusing and 5 being very easy to use. Over 80 percent of callers rated the ease of use a 4 or 5 (See Table 5). 


\section{Figure 9: Call Count Delineated by Zip Code}

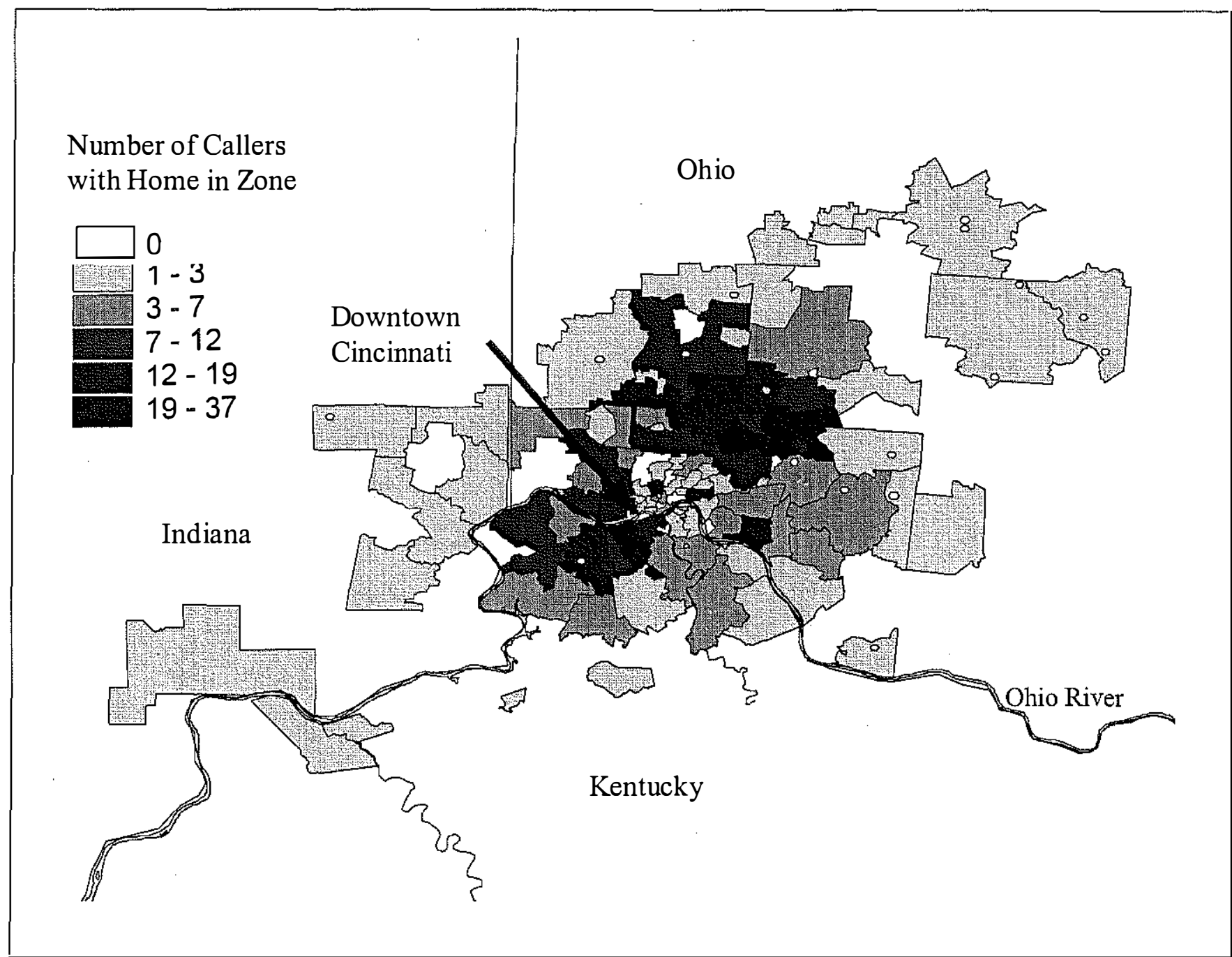

Note: There are several calls shown from rural areas. Information provided by the LEC to the KYTC shows a higher per capita number of calls from rural areas than from urban areas. 
Figure 10: Cellular Phone Ownership by Age

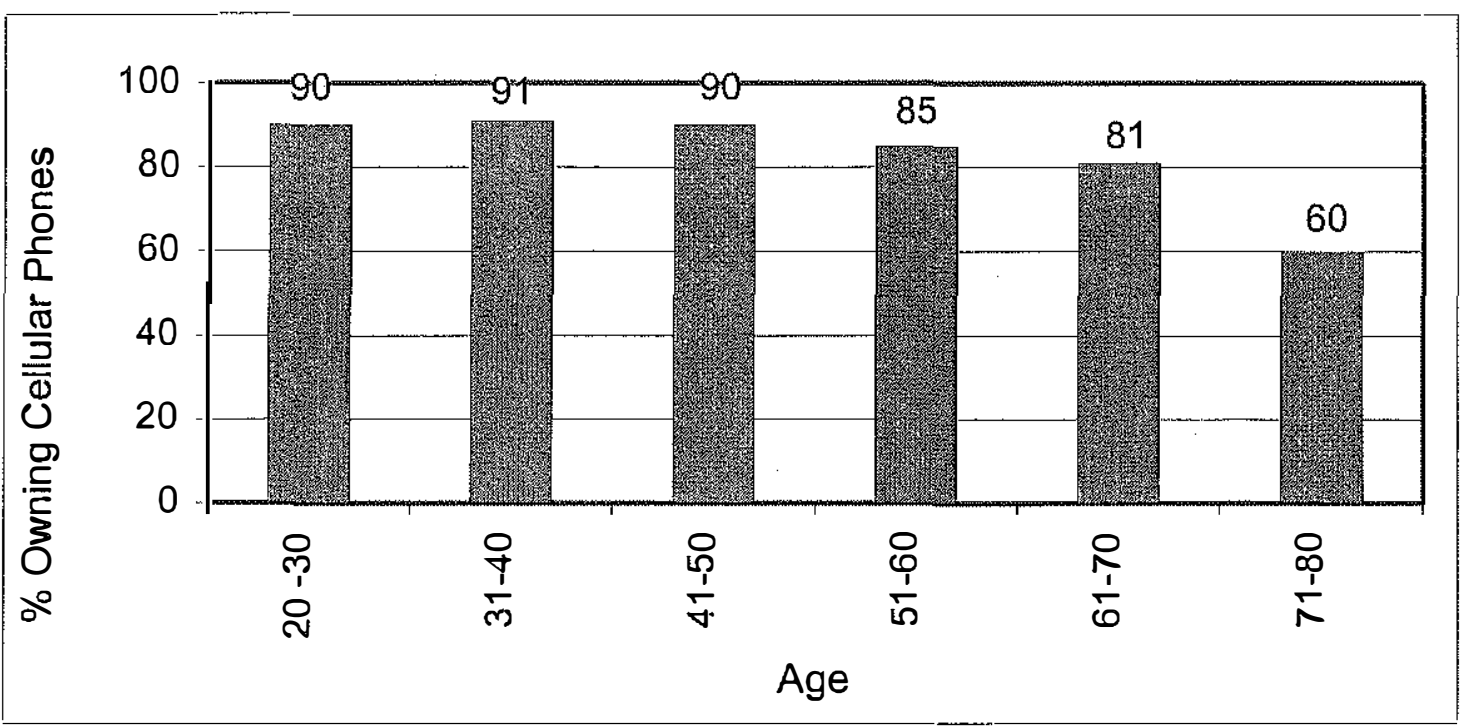

Figure 11: Cellular Providers of Callers

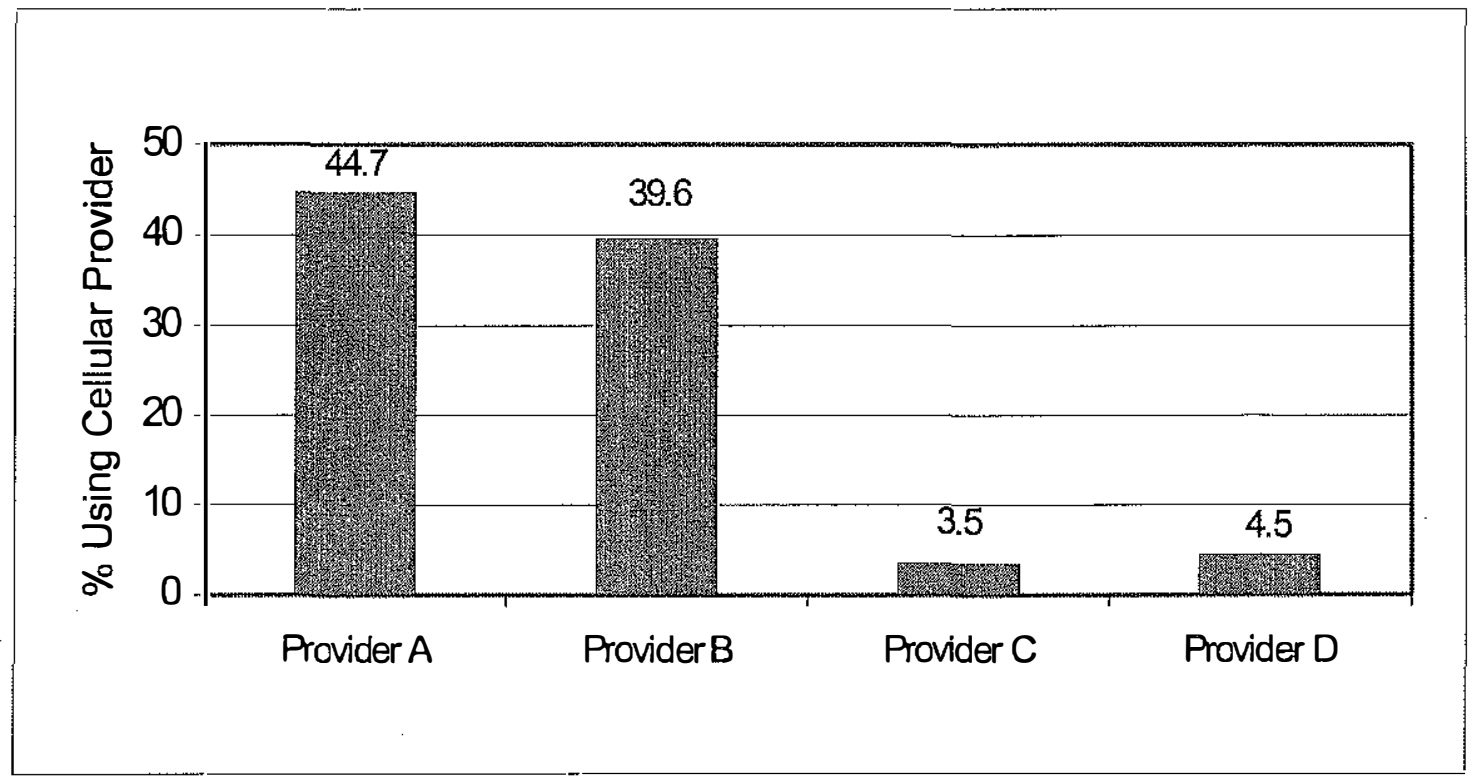


Figure 12: Overall Rating of ARTIMIS TATS

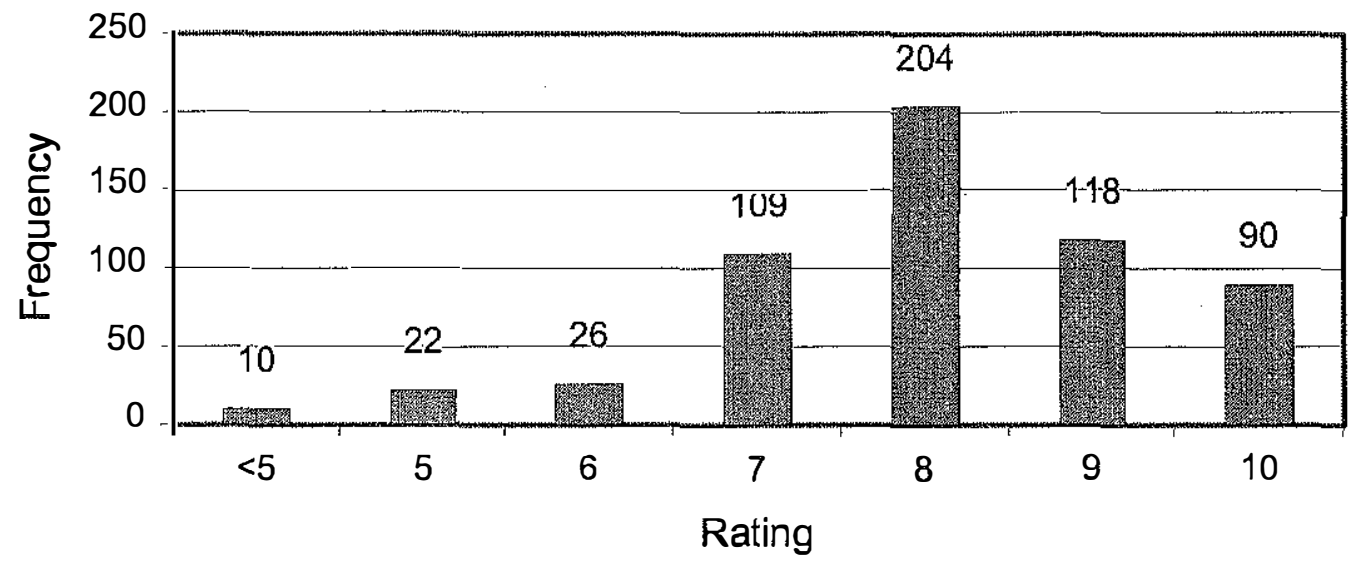

Figure 13: Perceived Benefits of ARTIMIS TATS

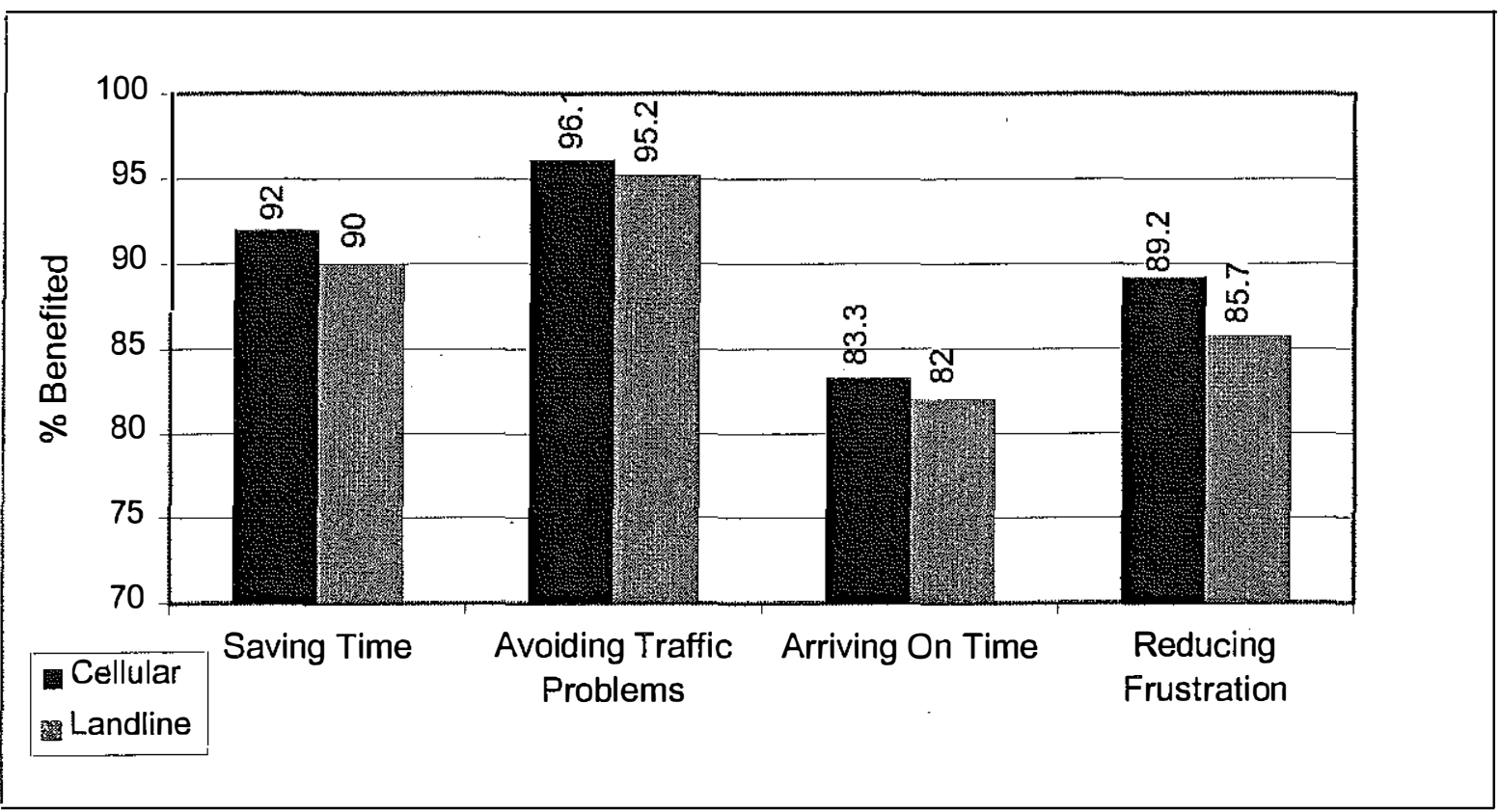


Table 4: Rating of the Accuracy of ARTIMIS TATS

\begin{tabular}{|c|c|}
\hline Rating & Frequency (\%) \\
\hline 1 (not accurate) & $3(0.5)$ \\
\hline 2 & $11(1.9)$ \\
\hline 3 & $75(13.0)$ \\
\hline 4 & $272(47.0)$ \\
\hline 5 (very accurate) & $215(37.1)$ \\
\hline
\end{tabular}

Table 5: Rating of the Ease of Use of ARTIMIS TATS

\begin{tabular}{|c|c|}
\hline Rating & Frequency $(\mathbf{\%})$ \\
\hline 1 (very confusing) & $7(1.2)$ \\
\hline 2 & $25(4.3)$ \\
\hline 3 & $67(11.6)$ \\
\hline 4 & $179(30.9)$ \\
\hline 5 (very easy to use) & $300(51.8)$ \\
\hline
\end{tabular}

Even the majority of suggestions for improvements to ARTIMIS TATS indicated a satisfaction with the service; people want more of it. Each participant was asked how they felt ARTIMIS TATS could be improved. While many (24.4 percent) of the people said that they could not suggest an improvement, extended service was the next most common answer. Extended service was considered as more frequent dates, weekend hours with live reports, and longer hours as well as extended spatial coverage of the system. Other suggestions related to message format and speed. Those responses and others can be seen in Table 6.

Table 6: Suggested ARTIMIS TATS Improvements

\begin{tabular}{|c|c|}
\hline Improvement & Times Mentioned (\%) \\
\hline None & $141(24.4)$ \\
\hline More Frequent Dates & $64(11.1)$ \\
\hline More Accurate Information & $61(10.5)$ \\
\hline Option to Bypass Messages & $53(9.2)$ \\
\hline Cover More Routes/Offer Alternate & $50(8.6)$ \\
\hline Less Confusing Codes & $44(7.6)$ \\
\hline Weekend Hours With Live Reports & $40(6.9)$ \\
\hline Longer Hours & $28(4.8)$ \\
\hline Slow Message Down & $18(3.1)$ \\
\hline
\end{tabular}




\subsection{Travel Behavior}

Travel behavior includes items such as origin and destination when making the call to ARTIMIS TATS, length of time and distance of the trip, and whether or not the trip was made alone. This section of the report also discusses the changes in travel behavior as a result of ARTIMIS TATS. Such behavioral changes could include taking a different route, changing departure time or destination, opting for another mode of transportation, or delaying the trip. Changes in travel behavior resulting from ARTIMIS TATS lead to many system benefits.

The survey indicated that 84 percent of calls to ARTIMIS TATS are made from vehicles. Home and work, equally, were the second most frequent origin of calls. However, people stated that they called from work more often and from home only occasionally. Figure 14 illustrates responses to these questions regarding locations people ever call from. Figure 15 illustrates the usual or most common location of callers and shows that most people (70.1 percent) were in their vehicle when calling ARTIMIS TATS. Obviously, 100 percent of these calls were made using a cellular phone. There were also a substantial number of people who usually called from home and work. Of those people calling from home and work, 48.8 and 53.7 percent, respectively, were using a cellular phone. Work was the trip destination of 40.1 percent and home was the destination of 32.1 percent, which suggests that most of the calls were home-to-work or work-to-home related. Trip types for men and women were very similar, with women running slightly more errands and driving to schools more often than men. Several calls were made for purposes other than work or home related trips, such as trips to the airport. The frequency of trip purposes is illustrated in Figure 16.

The mean distance of the usual trips the callers were taking was 22.1 miles and the trips took an average of 33.7 minutes. The average trip length of men versus women differed by less than a mile with women's trips being slightly longer. The trip length for cellular phone users was almost 4 miles longer than landline users. Thus, individuals spending more time in their car are more likely to own a cellular phone and to call ARTIMIS TATS. The respondents were asked how long in miles and minutes their trip was in order to calculate their mean speed. The calculated mean speed of all the trips was 44 miles per hour. This is not an unreasonable speed considering that the ARTIMIS TATS coverage area contains both Interstates and downtown city streets and many of the calls to the service were made during peak traffic hours.

The respondents usually made the trips alone. Figure 17 breaks down caller feedback in which they described themselves as "always", "mostly", "sometimes", or "never" being alone while making the trip. Approximately 70 percent of the respondents always made the trip alone. The figures suggest that carpooling is not a major factor when considering the people who call the service and that users may have the flexibility to change routes or departure times. However, when comparing cellular phone and landline users, cellular phone users are slightly more likely to be traveling with someone. Women travel with someone more often than men do. As noted earlier, women ran more errands and traveled to schools more often than men when calling for traffic information. This implies that women use the service while trip-chaining more than men. 
Figure 14: Locations That Callers EVER Call From

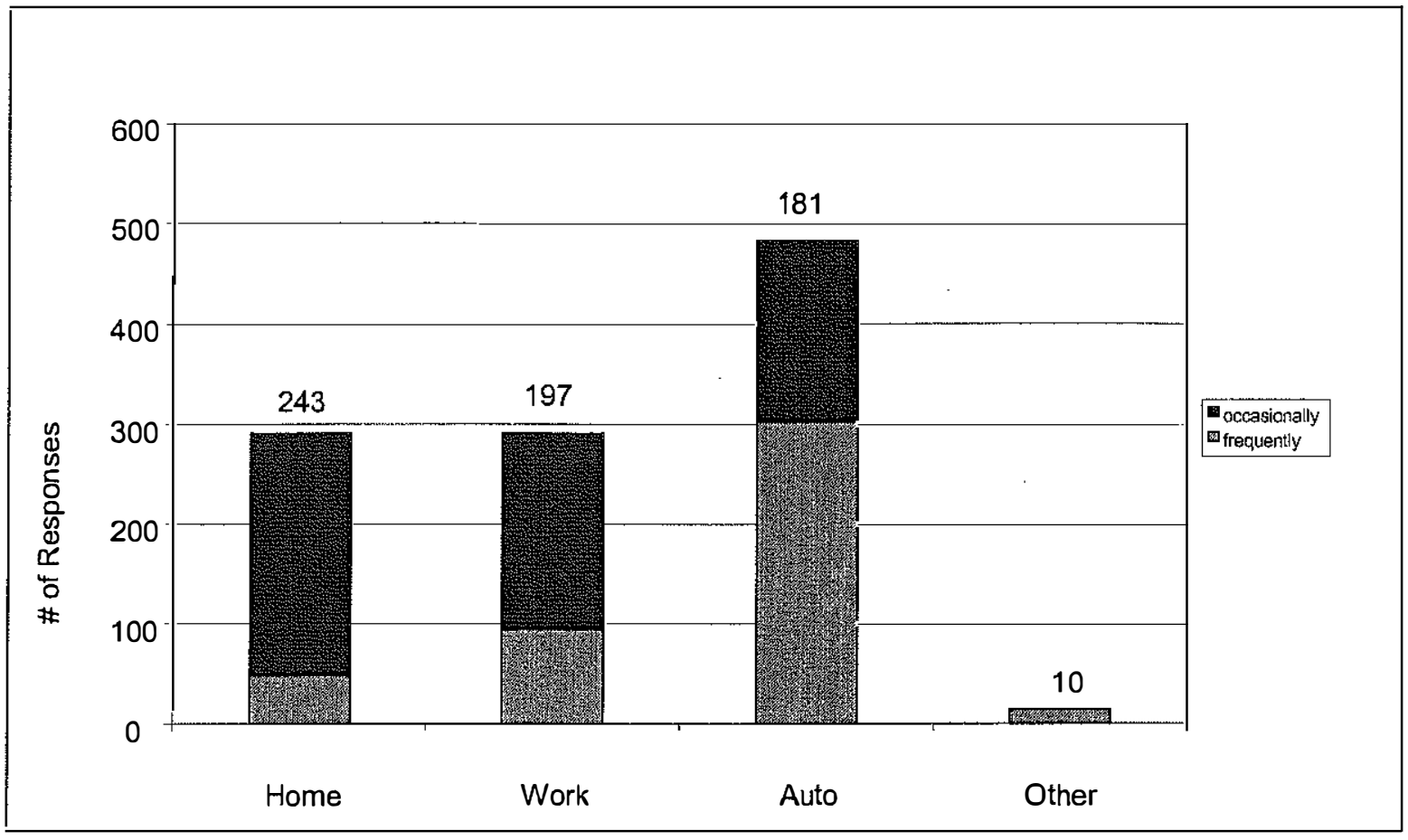

Figure 15: Locations That Callers USUALLY Call From

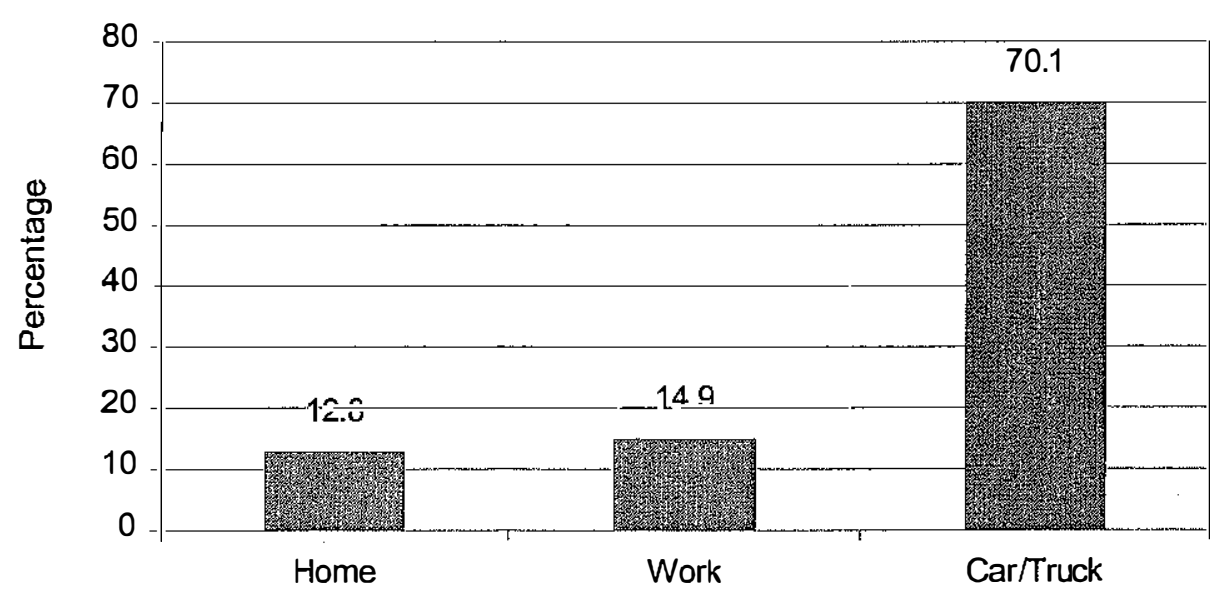


Figure 16: Trip Destination of ARTIMIS TATS Callers

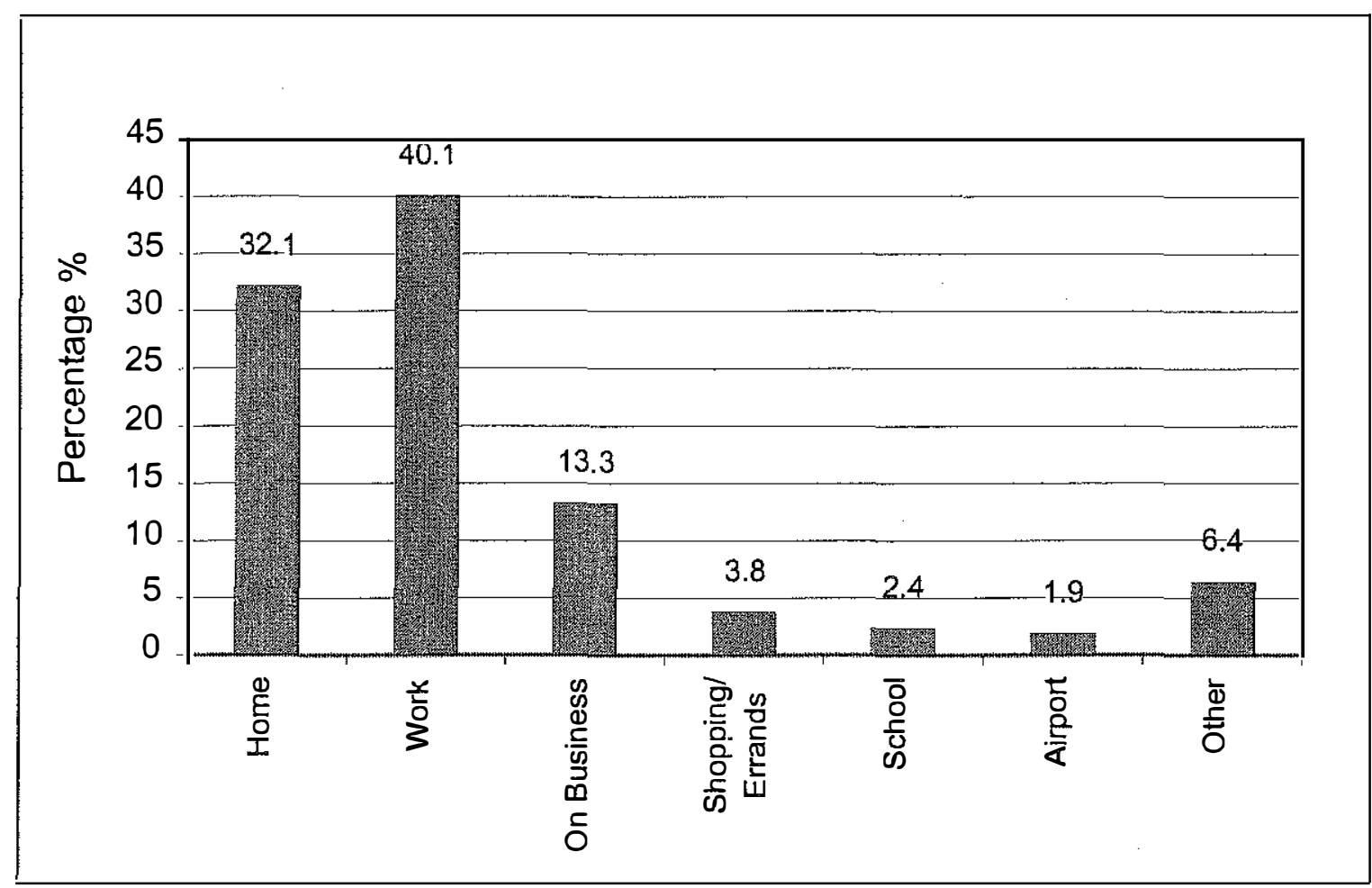

Figure 17: Frequency ARTIMIS TATS Users Travel Alone

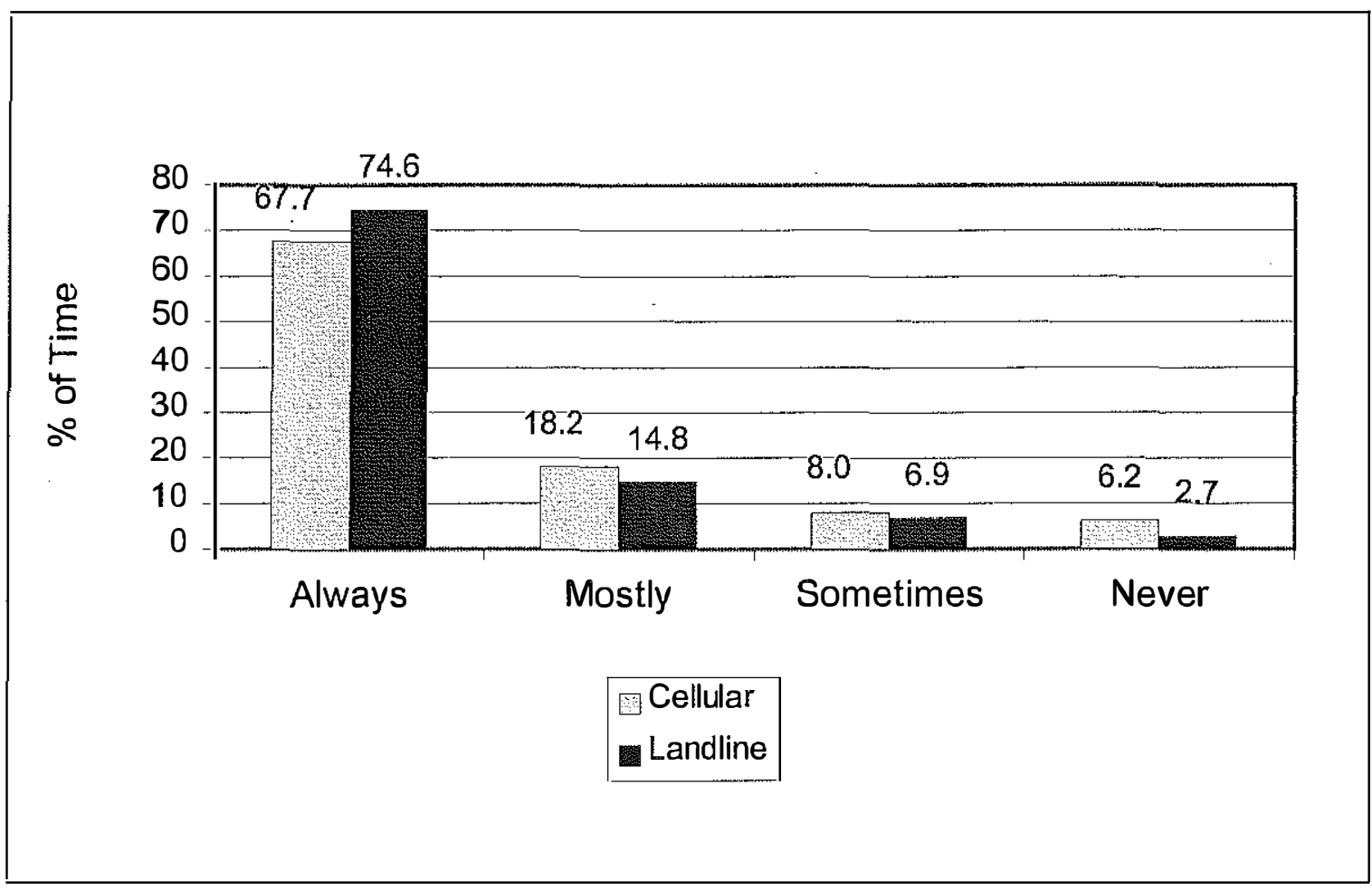


Callers who responded to the satisfaction survey were asked what percentage of the time the information they received from ARTIMIS TATS affected certain aspects of their travel behavior. This information is displayed in Figure 18. The route that the callers were taking was affected more frequently than any other aspect of their travel behavior at an average of 71.2 percent. This is a very high portion of the time that an ARTIMIS call affects people's routes. In addition to indicating a very positive system wide benefit this also suggests people with alternate routes to their destination may make up a large portion of the users than those without choice. The other common changes in travel behavior, in descending order, include departure time, destination, delay of trip, and mode of transportation. Few people were willing to change their destination or delay their trip.

Figure 18: Changes in Travel Behavior of ARTIMIS TATS Users

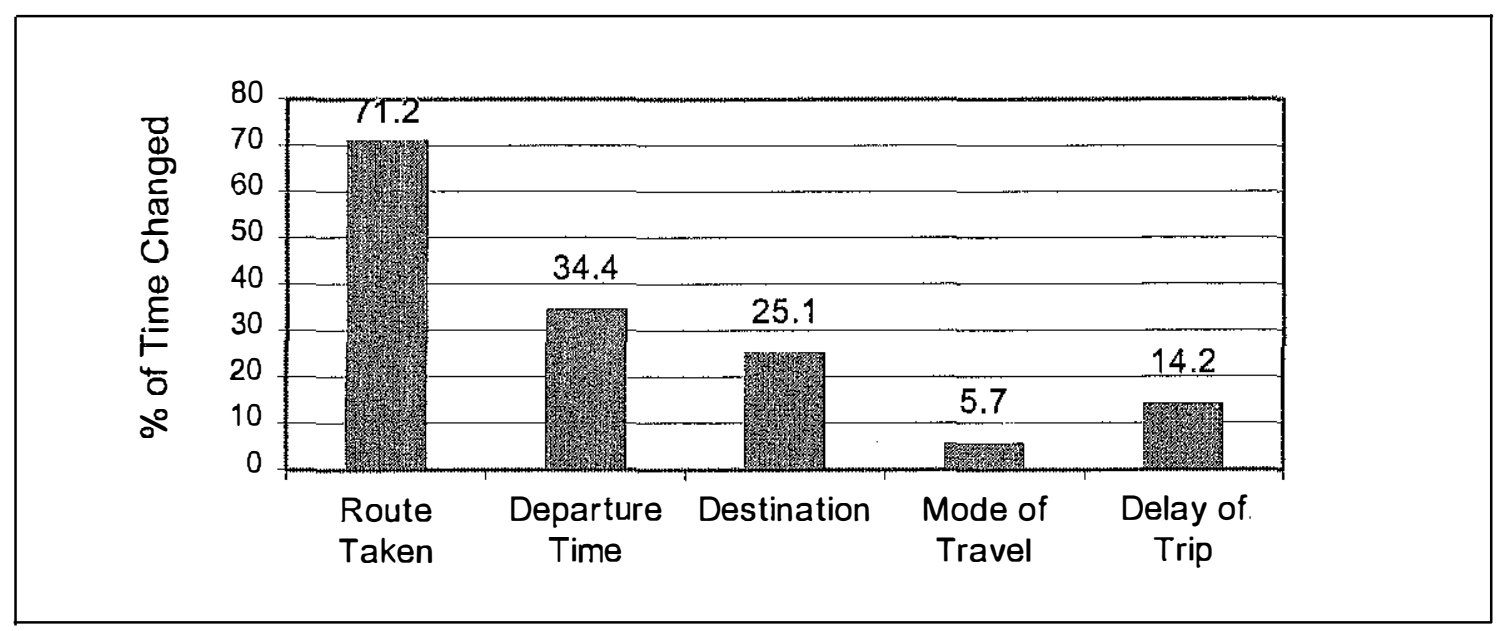

\subsection{Response to a Nationwide 211 Number}

In order to evaluate the potential success of a nationwide N11 dialing code for traveler information, questions were asked regarding trips to other cities and rural areas where the $\mathrm{N} 11$ dialing code would be helpful in providing traveler information. The respondents made an average of 19 trips per year to other cities where they felt they could use the national N 11 dialing code. These trips had an average length of 3 days. Only 4.3 percent (25 people) of those surveyed had used a telephone traveler information number in another city. Four of them lived in that city, 14 were visiting there, and 7 were just passing through. The respondents traveled an average of 19 times a year into a rural area where they had a need for travel information. Approximately 80 percent of the respondents felt that they would personally benefit from a nationwide N11 traveler information number so they did not have to know the local information service number for each area. 


\subsection{ARTIMIS TATS Access Numbers}

The intercept survey determined the access numbers people used to call ARTIMIS TATS. As noted earlier, 211 was used most often, followed by 333-3333 and 311, respectively. Respondents in the satisfaction survey were also asked to indicate which numbers they had ever used to contact ARTIMIS TATS. Of the 579 respondents, 78.9 percent had dialed 211, 31.6 percent had dialed 311 , and 24.9 percent had dialed 3333333.

Of the 122 callers who had never dialed 211 to reach ARTIMIS TATS, 45.9 percent were aware of the number. A total of 88.5 percent of the sample was aware of the 211 number, while only 58.2 and 47.6 percent were aware of the 311 and 333-3333 numbers, respectively. There was no significant difference between the percentage of Kentucky and Ohio callers who were aware of each number (recall Kentucky residents had access to a three digit number for a longer period of time). The awareness was 38.9 percent for the 311 number and 30.3 percent for the 333-3333 access number among those who had never used those numbers. Of those who did not own a cellular phone, 65.7 percent were aware of the 211 number. The 211 number is the most used and recognized number for the service.

\subsection{Callers' Use of the Service}

It is also important to know how the system is utilized. This study investigated when the callers started using the service, how many times per week they called, what time of day they most often called, and what motivated them to use the system. Other sources of travel information used by the callers were also of interest. Fifty-four percent of the callers have been using ARTIMIS just over a year. The average number of months was 13, but people claimed that they had known for anywhere from 0 to 50 months. All of this information is shown in Figure 19. 
Figure 19: Months Respondents Have Been Aware of ARTIMIS TATS

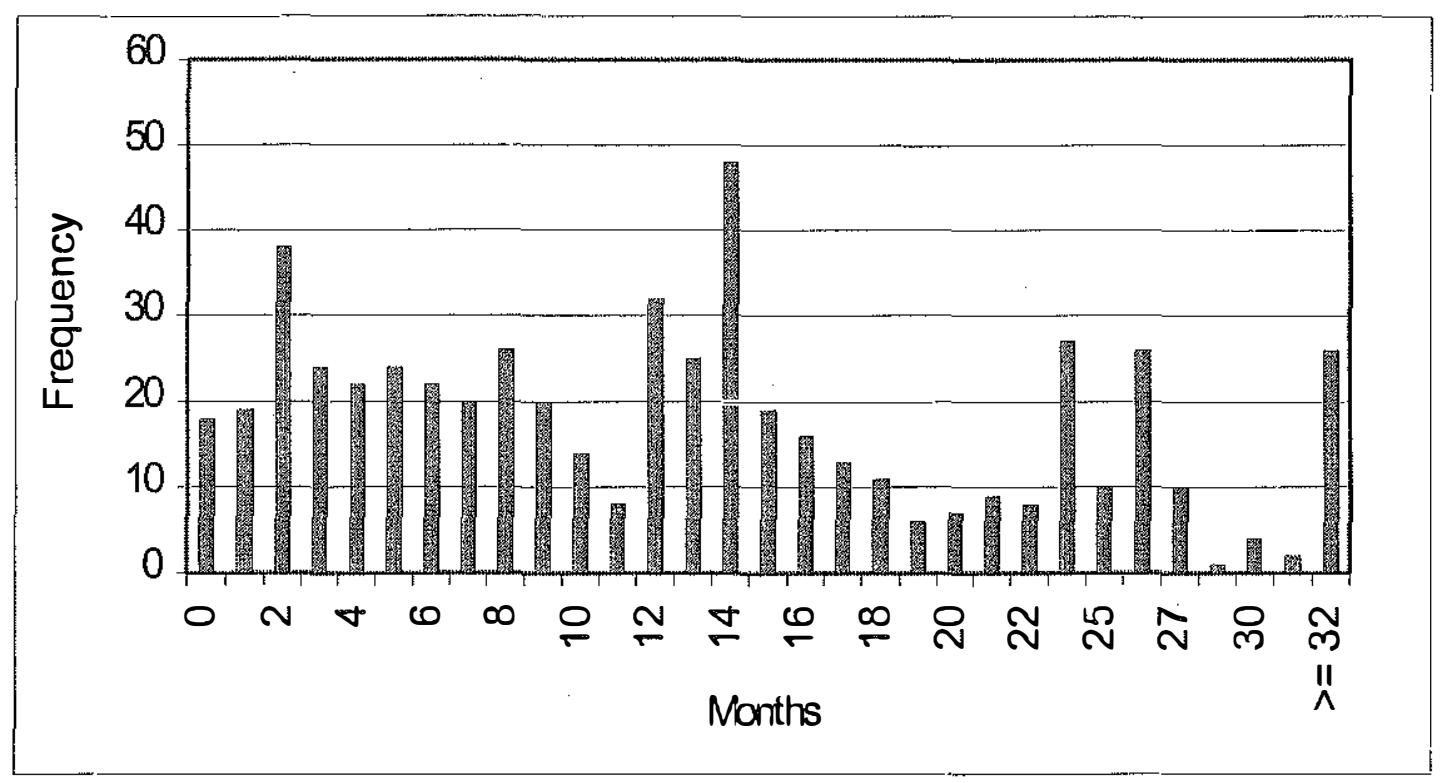

The calls per user of ARTIMIS TATS per week are also of interest. Calls per person ranged from 1 to 20 , with the average being 4.3 calls per week. The range of all of the responses is shown in Figure 20. Most people (79 percent) call 5 or fewer times per week. The majority of calls to the service are made during the times considered "rush hour", or the times when most people travel back and forth to work. Over 50 percent commonly call between 5 and 9 a.m., and over 80 percent call between 3 and 7 p.m. So, more people call during the afternoon "rush hour" than during the morning "rush hour". Times of calls are shown in Figure 21.

While calling ARTIMIS TATS may be a daily habit for some individuals, there are other factors that influence people to call. Survey respondents were asked how often situations such as bad weather, rush hour, running late, road construction, traffic crashes, and special events influenced them to contact ARTIMIS TATS for traveler information. Rush hour, traffic crashes and bad weather persuaded many people to call frequently while special events seldom promoted the use of ARTIMIS TATS. The lower frequency for special events could be contributed to the time availability of the service. The realtime traffic information is only of fered from 6:00 AM to 7:00 PM, Monday through Friday, while special events usually occur on nights or weekends. The trends for all the situations can be seen in Figure 22. 
Figure 20: Frequency of Calls to ARTIMIS TATS

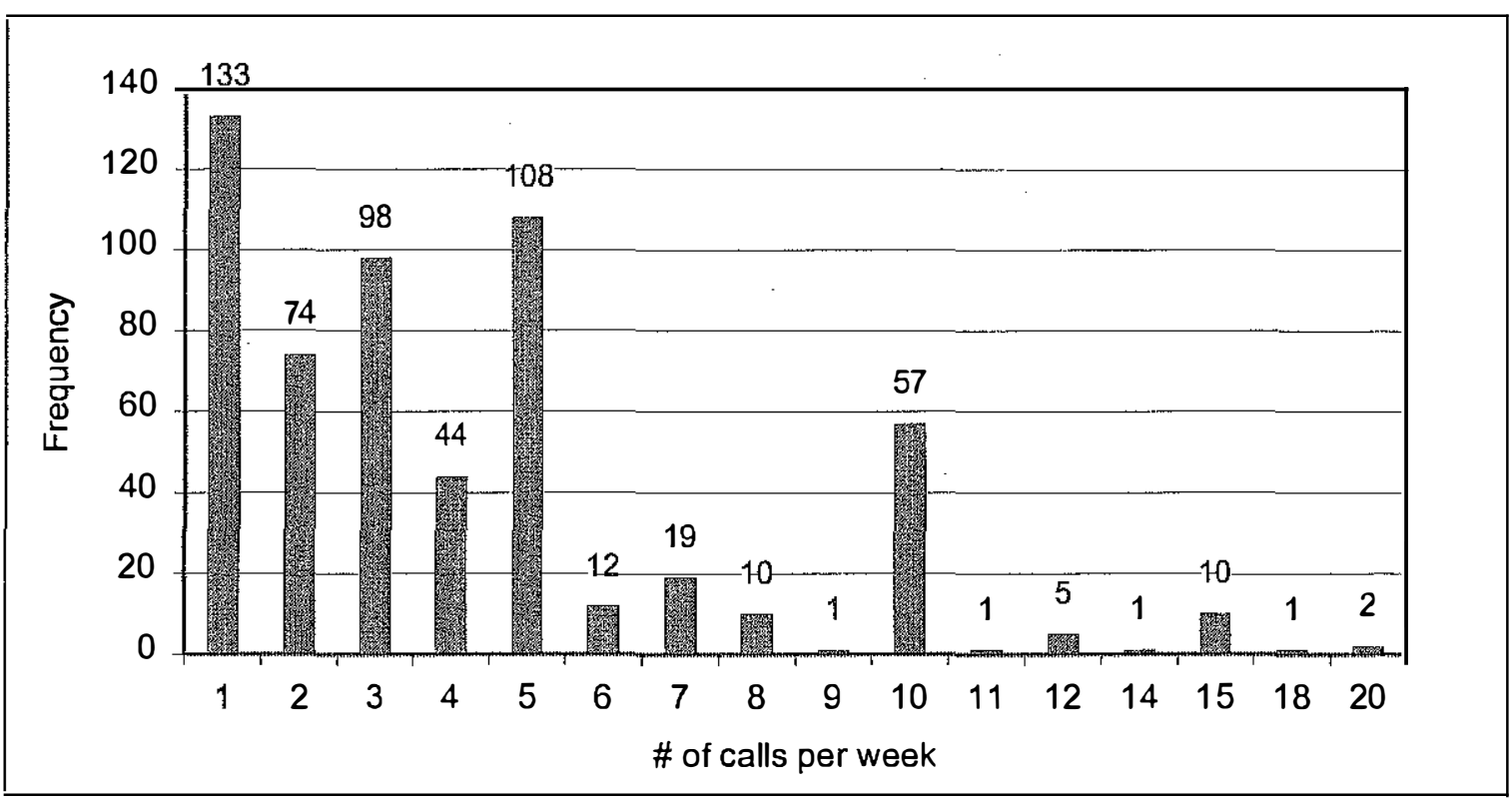

Figure 21: Time of Day When People Call ARTIMIS TATS

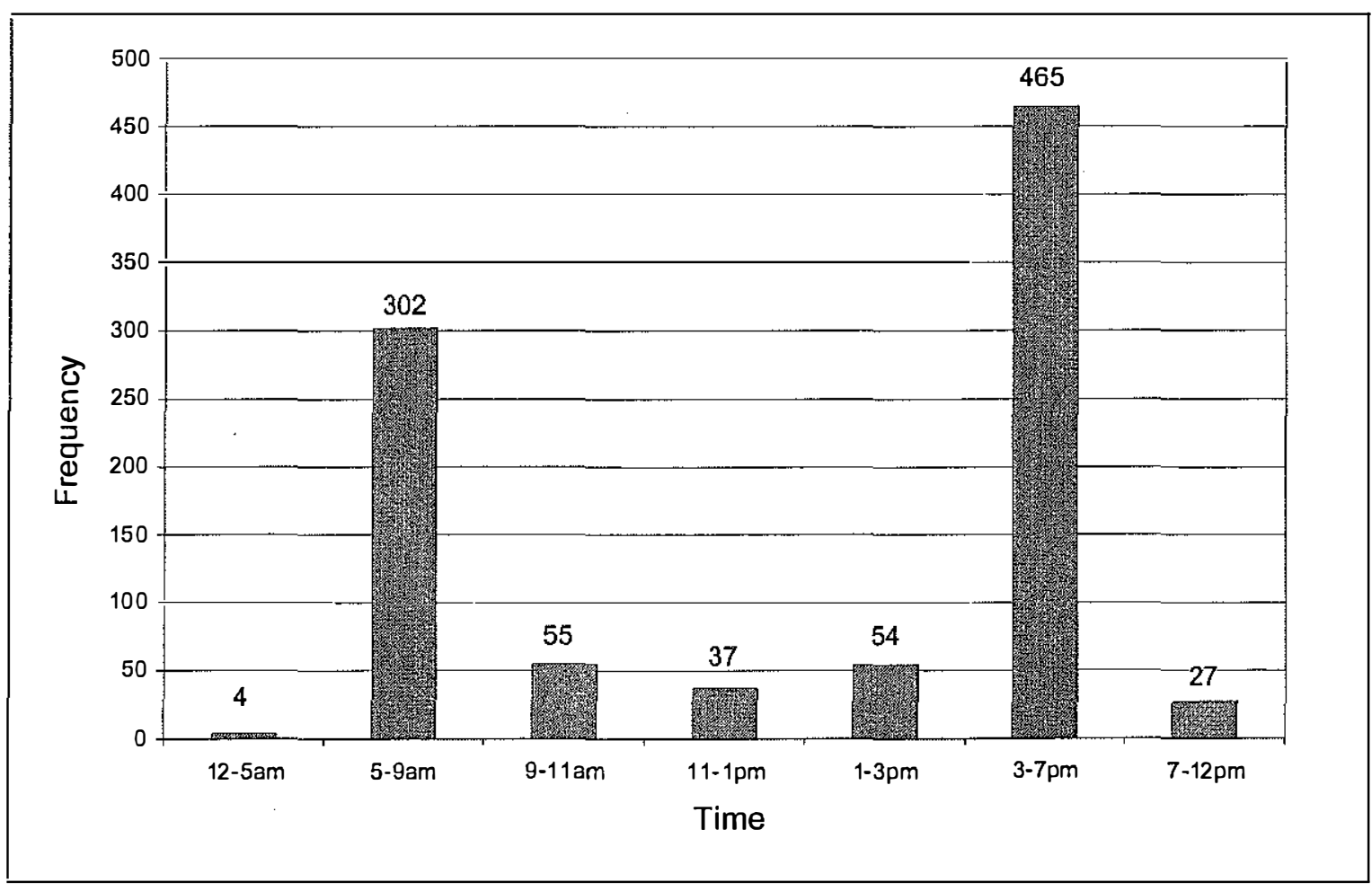


Figure 22: Motivation to Call ARTIMIS TATS

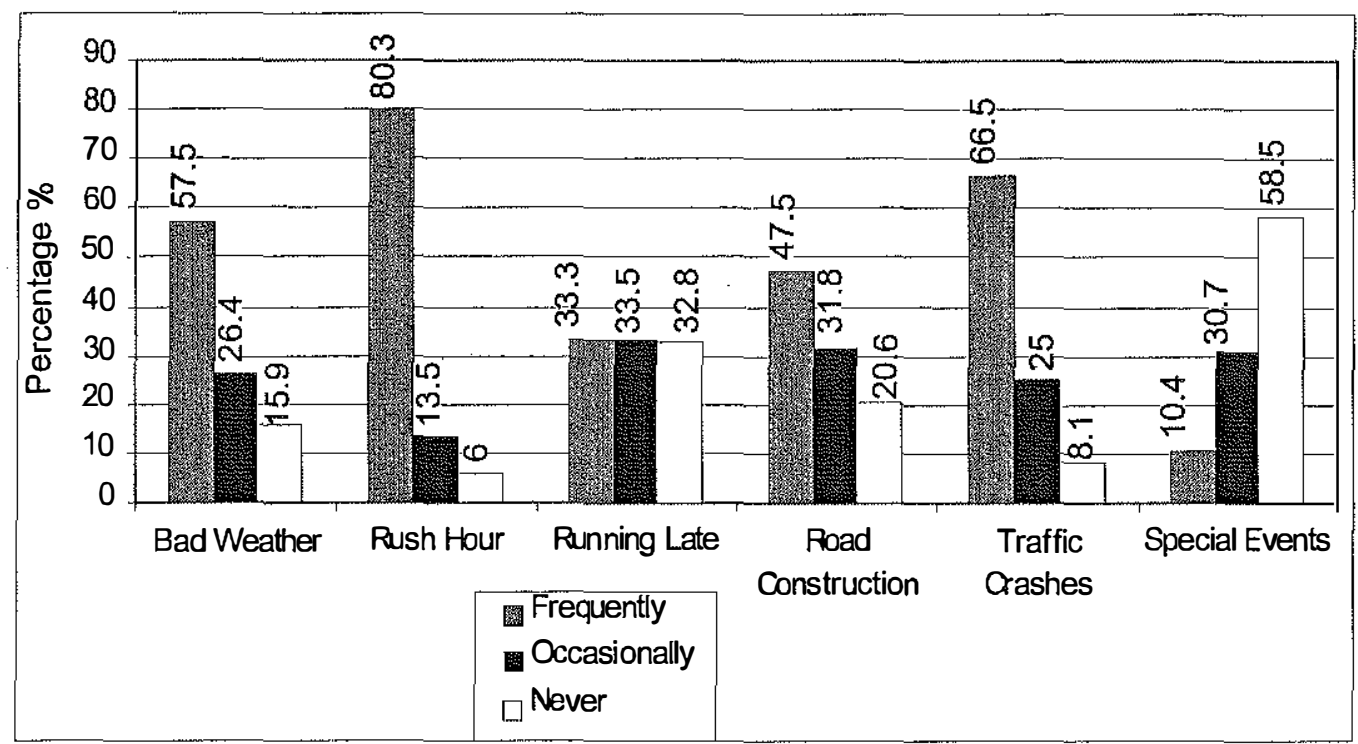

There are several other sources that the callers turn to for travel information. The leading source was the radio, with over 91 percent of the people using it. Television and changeable message signs over the freeways were used by 43 percent and 66 percent of the callers, respectively. The Internet and newspaper were also mentioned as sources. Fewer than 2 percent of the callers use no other source of travel information. Figure 23 indicates how many callers use each of the other sources of information.

\subsection{Effects of Advertising}

Use of advertising was discussed briefly in the Section 3.0. Radio broadcasts temporarily increased cellular phone calls and television broadcasts temporarily increased landline calls into ARTIMIS TATS. Radio was the means by which 34.2 percent of the survey respondents first became aware of ARTIMIS TATS. Television followed at 17.3 percent. Figure 24 also shows several other ways people leamed of ARTIMIS TATS, including word of mouth, road signs and cellular providers. The other category includes items with very small percentages, such as the Internet, pamphlets, and miscellaneous items. There were 26 people who did not know how they first discovered ARTIMIS TATS. Results of this section and the call history suggest that radio and television are the most successful means of advertising the service.

\subsection{Costs and Willingness to Pay}

A very important part of this analysis is cost, both to the user and to the public. There is also the issue of whether the user's perception of their cost is accurate. This is meaningf ul from a marketing point of view. Another area of interest is the maximum 
price that the caller is willing to pay for the service. A total of 96.4 percent of the respondents reported that it costs nothing to use ARTIMIS. Of those who believe they pay for the service, the average cost reported was $\$ 0.42$ per call. The cost incurred by 3.6 percent of the users may be due to roaming or long distance fees depending on calling location and/or cellular service provider.

Figure 23: Other Sources of Travel Information

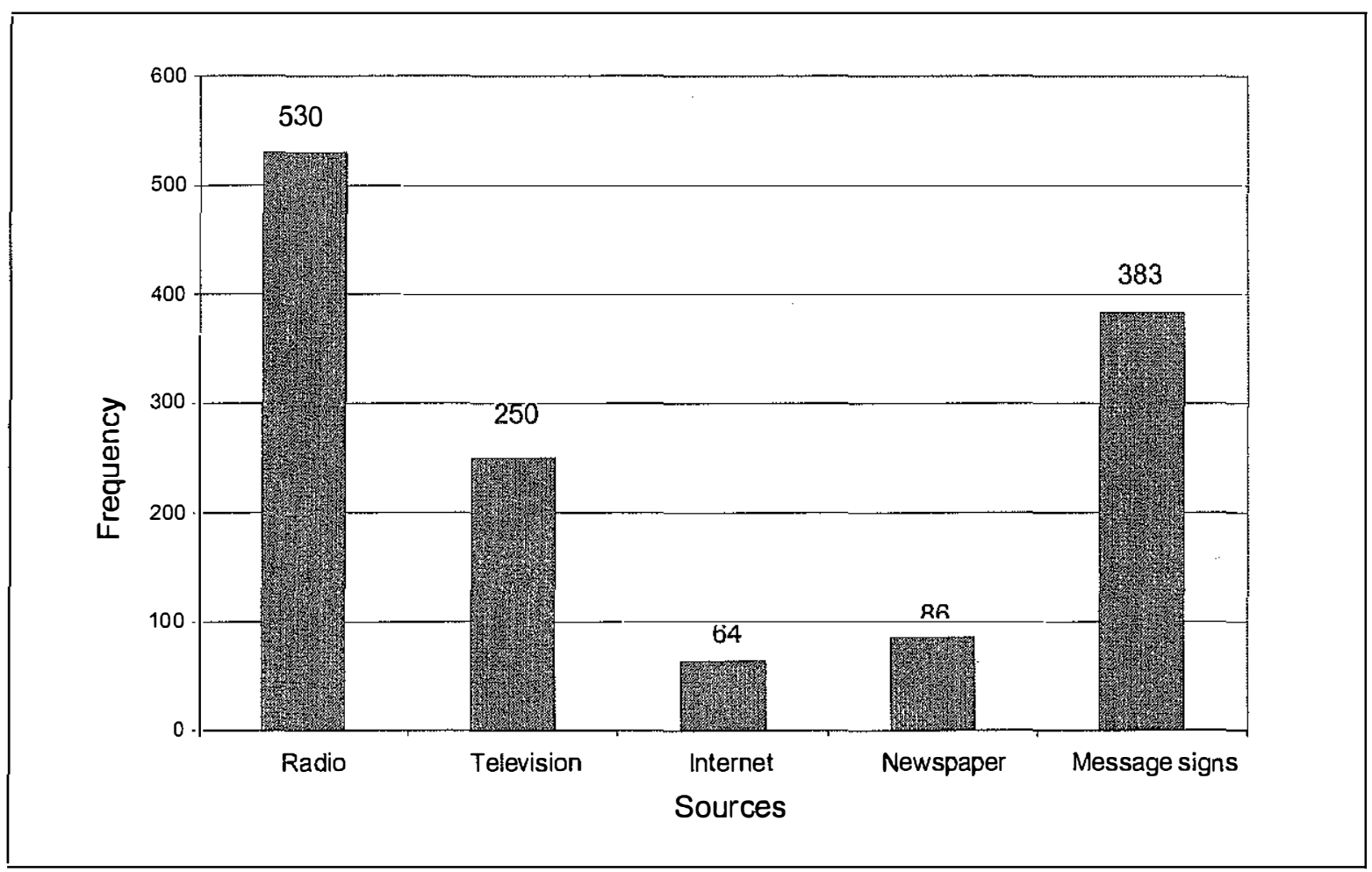

Figure 24: First Awareness of ARTIMIS TATS

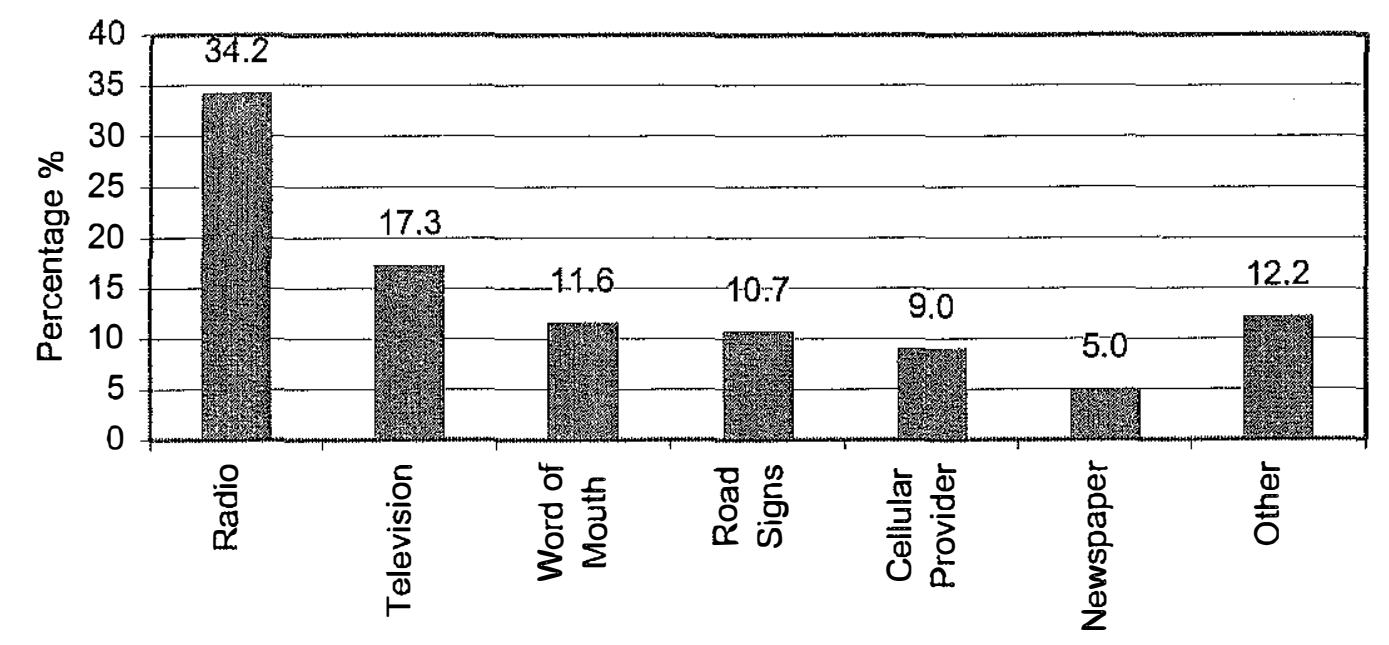


Users were asked what was the most that they would pay per call before discontinuing use of ARTIMIS TATS. The majority, 65 percent, said that they were willing to pay an average of $\$ 0.25$ per call. A little over 6 percent would pay one dollar or more, with 3 people indicating that they would pay $\$ 3$ for an ARTIMIS call.

The majority of users believe that they pay for ARTIMIS. This is in spite of the fact that only 3.6 percent reported directly paying anything to use ARTIMIS. Therefore, many users correctly believe that as tax payers, they indirectly pay for the service. A wide range of answers to the question concerning who pays for the service were reported and are shown in Figure 25.

\subsection{Characteristics of the Landline 211 Users}

Each time a user dials 211 from a landline phone, it costs ARTIMIS approximately $\$ 0.25$. In order to investigate this set of people and to see if they are different from other callers, further analysis was undertaken. Approximately 19 percent of users call 211 from a landline phone. A total of 56 percent of this group were male, and 44 percent were female. This is just slightly different than the overall usage breakdown of gender, 62 percent male and 38 percent female.

The average age of non-landline 211 callers was 43 years, while the average age of the landline 211 users was 48 . This 5 year difference could be related to the fact that fewer users over 70 years of age own cellular phones, as seen in Section 5.1. The highest level of education reached by the landline 211 callers was lower than that of the overall sample. There is no significant difference in the income of the landline 211 users and the income of the others in the sample.

There is a difference in the number of times per week the landline 211 users call ARTIMIS. Landline 211 users call only 3.5 times per week, as compared to 4.4 times per week overall. Also, landline 211 users call more frequently from home, about the same from work, and less frequently from their vehicles than the rest of the users. Landline 211 users change their departure time, change their destination, and postpone their trip more often than non-landline 211 users after calling the service. This may be because they have not started their trip yet and can change plans much easier than those that are already en route. Based on these results, the public receives benefits for the cost of landline 211 calls, as users change their travel plans and potentially improve overall system performance.

The analysis showed that the landline 211 callers do not always call from a landline phone. Over 70 percent of the landline 211 callers owned cellular phones, but that is considerably lower than the overall percentage of cellular phone owners, which was 88 percent. Landline 211 callers who own cellular phones reported on average calling ARTIMIS on a cellular phone 44 percent of the time. 
Figure 25: Who Do You Think Pays for ARTIMIS TATS?

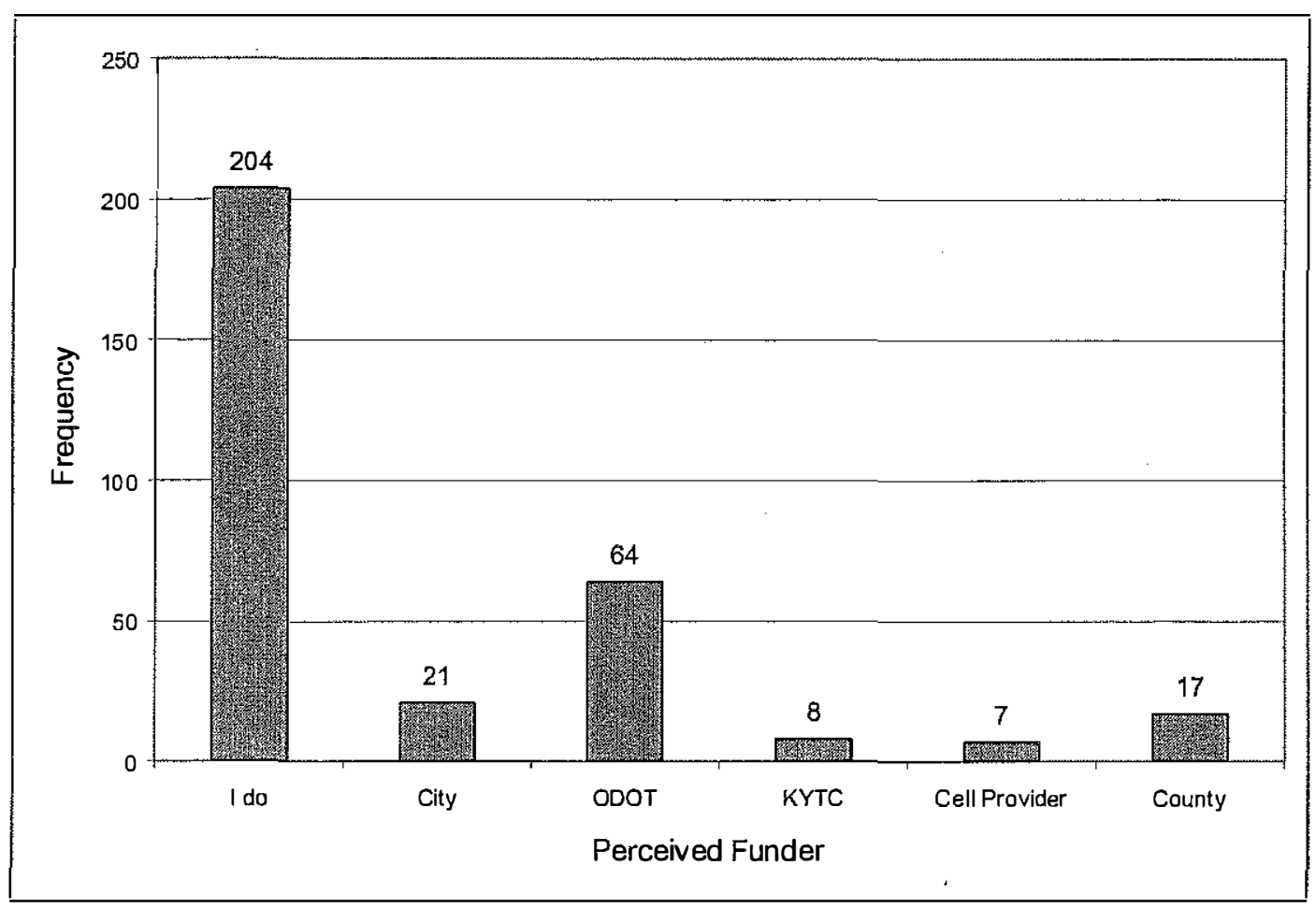

\subsection{CONCLUSIONS AND DISCUSSION}

This study consisted of a satisfaction survey conducted by telephone to evaluate ARTIMIS TATS available in the Cincinnati / Northern Kentucky Area. The objectives of this study were to: 1) assess the satisfaction with the service; 2) determine the prevalence and preference of access numbers for the service; and 3) determine how information provided by ARTIMIS TATS influences the ravel behavior. of its users.

In addition to evaluating ARTIMIS TATS, this study was also intended to assess the potential benefits of a nation-wide N11 dialing code for real time local traffic information. Real time traffic information has the potential to positively affect the overall transportation system performance. This study found users very often change their travel behavior, including route, departure time and destination in response to ARTIMIS TATS information. The 211 number was the most conumonly used and recognized number and 80 percent of respondents indicated they would personally benefit from a nation-wide N11 number. People indicated that they make on average 19 trips per year to other locations where they could use a service like ARTIMIS TATS. Furthermore, respondents indicated in several ways high satisfaction with the service including a willingness to pay for it. This potential use of telephone traffic information by the traveling public in multiple areas combined with 1) the high percentage of users who change their travel behavior due to real time information, 2) the overall satisfaction with ARTIMIS TATS, and 3) the good recall of the 211 number, suggests a nation-wide 3 - 
digit access code for traffic information would be a benefit to overall transportation system performance.

\subsection{Traveler Service Satisfaction}

Overall, the survey respondents were satisfied with the service, with an average rating of an 8.0 on a scale from one to ten, with ten being the best. Women rated ARTIMIS TATS slightly higher than men. Cellular and landline callers were equally satisfied with the service; however, cellular phone users claimed to benefit more from the information provided. Travelers perceived they benefited most by avoiding traffic problems, saving time, and reducing frustration. The users of ARTIMIS are benefiting from the service.

ARTIMIS TATS callers rated the accuracy and ease of use of ARTIMIS TATS very high. Survey respondents did, however, suggest several ways improvements could be made. Mentioned most often were expanded times of coverage and a larger coverage of travel routes in the area. Respondents also suggested that ARTIMIS make the codes from its menu easier to remember and to dial in a moving vehicle.

The majority ( 65 percent) of users was willing to pay for the service, further suggesting its value to them. This 65 percent stated an average of $\$ 0.25$ was the maximum acceptable payment for a single call. Cost perception answers suggest users are aware that the system is publicly funded and that most users do not incur a direct cost.

\subsection{Travel Behavior and Service Use}

Users are aware of the various numbers to contact ARTIMIS TATS. Although Cellular users were more likely to dial 211, many reported that they use both to contact ARTIMIS. Respondents had been users of ARTIMIS TATS on average 13 months and made an average of 4.3 calls per week. More people usually call in the afternoon peak ( 80 percent) than in the moming peak ( 50 percent). Survey respondents were motivated to call the service by rush hour, congestion, construction delays, traffic crashes, and bad weather. Most trips made while using the service were work-to-home or home-to-work related. Information received from ARTIMIS TATS was much more likely to affect the route taken than the departure time, destination, mode of transportation, or delay of trip.

\subsection{Nationwide N11 Traveler Information Dialing Code}

The 211 number used to access ARTIMIS TATS was the most used and recognized of the three access numbers available. Also, 211 is very popular among cellular users since many cellular providers allow access to the service without any airtime charges. The number's popularity and free airtime charges have positive implications for the newly requested nationwide N11 traveler information dialing code. Survey respondents made an average of 19 trips per year to other cities and 19 trips per year in rural areas where they said they could use an N11 dialing code to obtain local traveler information.

Approximately 80 percent of the respondents felt that they would personally benefit from a nationwide N11 dialing code, so they did not have to know the local information service number. Intercept and satisfaction surveys have provided information suggesting 
that the nationwide $\mathrm{N} 11$ traveler information dialing code would be beneficial to the traveling public.

Landline 211 calls in Cincinnati / Northern Kentucky result in a cost to ARTIMIS. These callers call less of ten but are more likely to change routes or delay trips. As such, there is a system performance benefit for the public investment in landline 211 . However, as 70 percent of these callers also own a cellular phone, future advertising should encourage cellular phone use and a reduction of the cost borne by the public. 


\section{APPENDIX}




\section{ARTIMIS 211 INTERCEPT SURVEY}

Date

Time

Read only what is in bold lettering.

Hello, my name is from the University of Kentucky Survey Research Center. In order to evaluate the quality of service provided by the SmarTraveler telephone information system and to improve its usef ulness to callers, I would like to ask five questions.

1. Which number did you dial to contact the traveler information system?

$$
211 \_311 \_333-3333
$$

2. Are you calling from a cellular phone?

_yes _ no

3. Would it be possible for us to call you sometime during the next two weeks to ask you more about your satisfaction with the traveler information system? The follow-up survey should only take about 5 minutes.

_yes__ no, Thank you for your time. I'll connect you to SmarTraveler now. [Connect to service.]

If yes, continue with survey.

4. May I please have a phone number where I can reach you in order to complete the survey?

5. May I please have your first name?

Thank you for your cooperation. I'll connect you to SmarTraveler now. [Connect to SmarTraveler] 
Hello, may I speak to [name of person previously contacted in intercept survey] ${ }^{5}$ My name is [\#\#\#\#] from the University of Kentucky Survey Research Center. Recently you called the ARTIMIS SmarTraveler telephone traveler information service and agreed to answer some follow-up questions regarding the service. This survey should take less than 10 minutes, and your completely confidential feedback would be very helpf ul to us. Is this a good time?

1. Are you a licensed driver AND 18 years of age or older?

Yes

No (if no, end survey)

$\mathrm{DK}^{6}$

$\mathrm{REF}^{7}$

2. On average, how many times per week do you call ARTIMIS SmarTraveler?

[Enter in \# of times per week]

3. During what month and year did you begin using SmarTraveler?

[INTERVIEWER: IF THEY SAY A SEASON; TRY TO GET AN APPROXIMATE MONTH]

[Multipunch]

Month

Year

DK

REF

4. How did you first become aware of ARTIMIS SmarTraveler's telephone information service?

Internet

TV

Radio

Word of mouth

Newspaper

Other

DK

REF

Other source of awareness.

Open end

5. Overall, on a scale of 1 to 10 , with 10 being the best, how would you rate the SmarTraveler service?

[Enter in \# from 1-10]

Numeric Open End

${ }^{5}$ Information in [ ] are instructions to those performing the survey.

${ }^{6}$ Used when the respondent did not know the answer to the question.

${ }^{7}$ Used when the respondent refused to answer the question. 
6. Please tell me if you ever call ARTIMIS SmarTraveler from any of the following locations:

Home

Work

Car/Truck

Other

DK

REF

Other location.

Open end

7. From those locations, where do you call from most of ten?

Home

Work

Car/Truck

Other

DK

REF

Other place.

Open end

8. What time of day do you routinely call the service? [Can answer all that apply.] Midnight - 5:00 am

5:00 - 8:59 am

9:00 - 10:59 am

$11: 00-12: 59 \mathrm{pm}$

$1: 00-2: 59 \mathrm{pm}$

3:00 - 6:59 pm

7:00 - 11:59pm

DK

REF

9. Typically, where are you GOING when you make the call from [Question \#7]?

Home

Work

On Business

Shopping

Errands

Other

DK

REF

Other destination.

Open end

10. Approximately how many miles is the one-way trip to this destination?

[Enter number of miles].

Numeric Open End

11. Approximately how long is the one-way trip in minutes to this destination?

[Enter number of minutes].

Numeric Open End 
12. On that trip, how of ten are you driving alone? Is it:

Always

Mostly

Sometimes

Never

DK

REF

13. How of ten do you call ARTIMIS SmarTraveler from home, frequently, or only occasionally? ${ }^{8}$

Frequently

Occasionally

DK

REF

14. How of ten do you call ARTIMIS SmarTraveler from work, frequently, or only occasionally?

Frequently

Occasionally

DK

REF

15. How often do you call ARTIMIS SmarTraveler from your car/truck, frequently, or only occasionally?

Frequently

Occasionally

DK

REF

16. How often do you call ARTIMIS SmarTraveler from [Q ]\#\#, frequently, or only occasionally? Frequently

Occasionally

DK

REF

How of ten do the following situations motivate you to call ARTIMIS SmarTraveler:

Frequently, Occasionally, or Never:

17. Bad weather? [motivates you to call ARTIMIS SmarTraveler]

Frequently

Occasionally

Never

DK

REF

${ }^{8}$ Questions \#13-16 are only asked for those answers given in Question \#6. 
18. Rush hour? [motivates you to call ARTIMIS SmarTraveler]

Frequently

Occasionally

Never

DK

$\mathrm{REF}$

19. When you're running late? [motivates you to call ARTIMIS SmarTraveler]

Frequently

Occasionally

Never

DK

REF

20. Road construction? [motivates you to call ARTIMIS SmarTraveler]

Frequently

Occasionally

Never

DK

REF

21. Traffic accidents? [motivates you to call ARTIMIS SmarTraveler]

Frequently

Occasionally

Never

DK

REF

22. Special events? [motivates you to call ARTIMIS SmarTraveler]

Frequently

Occasionally

Never

DK

REF

Approximately what percent of the time does the information you received through the telephone information service affect the following:

23. The route you take?

[Enter number for percentage].

Open end

24. Your departure time?

[Enter number for percentage].

Open end

25. Your destination?

[Enter number for percentage].

Open end 
26. Your mode of transportation, such as taking the bus instead of driving the car? [Enter number for percentage].

Open end

27. A decision to make or postpone a trip?

[Enter number for percentage].

Open end

Overall, in which of the following ways do you feel you have benefitted from ARTIMIS SmarTraveler services:

28. Saving time?

Yes

No

DK

REF

29. Avoiding traffic problems? [a benefit of SmarTraveler, overall]

Yes

No

DK

REF

30. Arriving at your destination on time? [a benef it of SmarTraveler, overall]

Yes

No

DK

REF

31. Reducing frustration? [a benef it of SmarTraveler, overall]

Yes

No

DK

REF

32. Besides ARTIMIS SmarTraveler, which of the following other sources of travel information do you use:

[multipunch]

Radio

Television

Internet

Newspaper

Changing message signs over the freeway

Other sources of information.

Open end.

33. Have you ever recommended the telephone traveler information service to a friend? Yes

No

DK

REF 
34. Based on your past calling experience, please rate the overall accuracy of the information you received on a scale from 1 to 5, with 1 being not accurate at all and 5 being very accurate.

Not accurate at all

2

3

4

Very accurate

DK

REF

35. Also, please rate the overall EASE OF USE of the phone service on a scale from 1 to 5 , with 1 being very confusing and 5 being very easy to use.

Very confusing

2

3

4

Very easy to use

DK

REF

36. How could the service be improved?

Open end.

37. What phone number(s) have you used to contact ARTIMIS SmarTraveler?

[Interviewer: do not prompt, but you can verify.]

211

311

333-3333

DK

REF

38. Did you know you can dial the phone number 211 to contact ARTIMIS SmarTraveler? Yes

No

DK

REF

39. Were you aware of the phone number 311 previously used to contact ARTIMIS SmarTraveler?

Yes

No

DK

REF

${ }^{9}$ Questions \#38-40 will only be asked based upon the response to Question \#37. 
40. Did you know you can dial the phone number 333-3333 used to contact ARTIMIS SmarTraveler?

Yes

No

DK

REF

41. Do you have the ARTIMIS SmarTraveler number programmed into your phone? Yes

No

DK

REF

42. What does it cost you to call SmarTraveler, per call?

Numeric Open end.

43. What is the most you would pay per call before you would stop using the ARTIMIS SmarTraveler service?

Open end.

44. Did you know you can call 211 to reach SmarTraveler for free anywhere in the greater Cincinnati or Northern Kentucky area?

Yes

No

DK

REF

45. To the best of your knowledge, who pays for the SmarTraveler information service? [Multipunch; DO NOT READ CATEGORIES]

I pay for the calls

City

Ohio Department of Transportation

Ky. Transportation Cabinet/ Ky. Department of Transportation

Cellular Phone Providers

County

Highway Department

Federal Govemment

Private Sources

Taxpayers

Other

DK

REF

46. On average, how many trips a year do you travel in other cities where you could use a service like this?

Numeric open end.

47. Approximately how many days is your average trip? ${ }^{10}$

Numeric open end

${ }^{10}$ Question \#47 is only asked is answer to Question \#46 is greater than zero. 
48. Have you used a telephone traveler information service in another city?

Yes

No

DK

REF

49. Did you live there, were you visiting there, or just passing through? ${ }^{11}$

Lived there

Visiting there

Just passing through

DK

$\mathrm{REF}$

50. Would you personally benefit from a NATIONWIDE 211 traveler information number so you do not have to know the local information service number for each area?

Yes

No

DK

$\mathrm{REF}$

51. How many times per year are you in a rural or small-town area where you wished there was a number you could call for travel information?

[Enter number].

Open end

52. [INTERVIEWER: RECORD GENDER WITHOUT ASKING]

Male

Female

The last few questions are so we can see if different types of people have different opinion about the service.

53. First, do you have a cellular phone?

Yes

No

DK

REF

54. Who provides your cellular phone service? ${ }^{12}$

[Enter company].

Open end.

55. When calling SmarTraveler, what percentage of the time do you use a cellular phone? [Enter number].

Open end

${ }^{11}$ Question \#49 is only asked if answer to Question \#48 is yes.

${ }^{12}$ Questions \#54 and 55 are only asked if response to Question \#53 is yes. 
56. What is your zip code?

[Enter number].

Open end.

57. What year were you born?

[Enter year 19XX].

Open end.

58. What was the highest level of education that you completed?

Grade school (through grade 8)

Some high school education (not a graduate)

High school graduate or GED

1 to 3 years or college

4 years of college, or college degree

Postgraduate work or degree

DK

REF

59. Which of the following best describes your average household annual income? [INTERVIEWER: IF THEY SAY A NUMBER EXACTLY ON CATEGORY BREAK, RECORD IN THE HIGHER CATEGORY]

Less than $\$ 15,000$

$\$ 15,000$ to $\$ 25,000$

$\$ 25,000$ to $\$ 35,000$

$\$ 35,000$ to $\$ 45,000$

$\$ 45,000$ to $\$ 55,000$

$\$ 55,000$ to $\$ 65,000$

$\$ 65,000$ to $\$ 100,000$

$\$ 100,000$ or more

Those are all the questions we have. Thank you for your time!

Respondents understanding was:

Excellent

Good

Fair

Poor 